\title{
Intermediate Phases in Superconducting Niobium-Tin Alloys
}

\author{
L. L. Wyman, J. R. Cuthill, G. A. Moore, J. J. Park, and H. Yakowitz
}

(April 13, 1962)

\begin{abstract}
In attempting to produce superconducting wire of the niobium sheath $\mathrm{Nb}_{3} \mathrm{Sn}$ core type, it became apparent that results were generally unpredictable. Metallographic examination showed that such materials are heterogeneous and contain a number of intermediate phases. Detailed metallographic studies were made on diffusion zones in which tin had been allowed to react with porous niobium blocks, with fused niobium rod, and with niobium wires, and on a number of reacted powder mixtures.

The phases produced were identified by anodizing to characteristic colors and by microspot analysis, supplemented by some hot-stage microscope and thermal analysis tests. On the basis of these observations, a tentative revised diagram is offered to illustrate the types of reactions which occur in the system.

The presumably desired phase, $\mathrm{Nb}_{3} \mathrm{Sn}$, is found to lie between the more easily formed phases $\mathrm{Nb}_{4} \mathrm{Sn}$ and $\mathrm{Nb}_{2} \mathrm{Sn}_{3}$, which are stable to temperatures well above the peritectoid decomposition of the $\mathrm{Nb}_{3} \mathrm{Sn}$. At lower temperatures the compound $\mathrm{Nb}_{2} \mathrm{Sn}$ is formed. It is indicated that the high-temperature treatment to react niobium and tin should be followed either by very slow cooling or by an anneal in the 600 to $700{ }^{\circ} \mathrm{C}$ range to form $\mathrm{Nb}_{3} \mathrm{Sn}$.
\end{abstract}

\section{Introduction}

When the results from the initial investigations of the superconducting properties of the niobium-tin alloy " $\mathrm{Nb}_{3} \mathrm{Sn}$ " were first disclosed, the Chemical Metallurgy Section was requested by the NBS Cryogenic Engineering Laboratory at Boulder, Colo., to produce some of this material. This was accomplished in a manner subsequently revealed in the initial report of Kunzler et al., [1] ${ }^{1}$ concerning the properties of this material. The outstanding performance of this NBS-produced wire was disclosed by Arp, Kropschot, and Wilson [2].

Although the original objective had been the attainment of an alloy, or rather an intermetallic compound of " $\beta$-Tungsten" structure, having the composition $\mathrm{Nb}_{3} \mathrm{Sn}$, the actual result of the processing of the material was shown by preliminary metallurgical investigations to be something quite different. The fact that the alloys prepared by any of several methods consisted of from four to six or seven different metallurgical constituents has been known and privately reported by this and other metallurgical laboratories.

This disclosure has profound significance in several areas. It must be recognized that we have not been dealing with a directly formed homogeneous material. Also, if it is correct to assume that only the $\mathrm{Nb}_{3} \mathrm{Sn}$ phase has the desired superconducting properties, a minimum requirement is to achieve a continuity of this phase throughout the length of the conductor. A simplified "filament" or "thread" hypothesis, which tacitly assumes that when the resistivity is zero an infinitely small conducting path

\footnotetext{
${ }_{1}$ Figures in brackets indicate the literature references at the end of this paper.
}

can carry an infinitely large current, is not sufficient to characterize a practical superconductor; it does not take into account the concept of "quality," whereby one specimen can carry more current, or resist a higher magnetic field, than can another specimen of the same size. Nevertheless, one can presume that any superconducting alloy wire does not necessarily need to be homogeneous, but does at least require one or more continuous paths of the desired superconducting constituent throughout the length of the conductor.

Initially, the superconductor, $\mathrm{Nb}_{3} \mathrm{Sn}$, was prepared by Matthias [3] who described its electrical properties. At a later date, Kunzler [1] arrived at several modes of $\mathrm{Nb}-\mathrm{Sn}$ alloy preparations and treatments. However, the metallurgist realized, from previous experience with other systems, that treatment of niobium, with its extremely high melting point, and of tin, with its extremely low melting point, at temperatures far from the melting point of either could only result in extreme heterogeneity.

Experience in other laboratories had shown that, not infrequently, wires produced in the manner suggested by Kunzler failed to show the desired superconducting properties. As a consequence of all of these factors, it became evident that the physical metallurgy of this alloy formation would need to be carefully investigated if the process were to be adequately controlled. Previous to the interest in its superconducting properties, this alloy system had received but little metallurgical attention. A constitutional diagram of the binary $\mathrm{Nb}-\mathrm{Sn}$ system was proposed by Savitskii et al. [4], figure 1. The only constituent shown, other than the terminal phases of the component metals, is the intermetallic compound $\mathrm{Nb}_{3} \mathrm{Sn}$, which is indicated as having been 


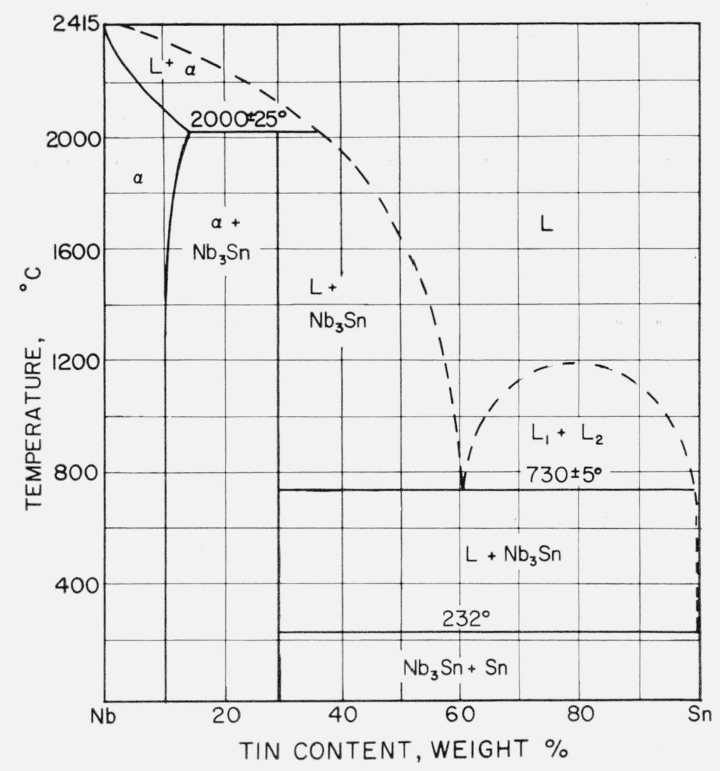

Figure 1. Constitution diagram of the niobium-tin system according to Savitskii et al., [4].

formed by a peritectic reaction near $2000{ }^{\circ} \mathrm{C}$. These authors detected a reaction horizontal near $730{ }^{\circ} \mathrm{C}$ which they attribute to the presence of a monotectic between two tin-rich liquids.

The Savitskii diagram is certainly not compatible with the large number of phases which have been observed by microexamination of the alloy wires. Thus, the system must be further studied in order to identify positively the various phases and to establish the conditions for their formation.

\section{Experimental Procedure}

Rather than endeavoring to use the extremely fine wires prepared for superconducting experiments as subjects of metallurgical study, it was decided to use massive specimens. Diffusion studies were conducted using semi-sintered bars made from rather coarse-grained niobium powder. ${ }^{2}$ These were partially immersed in baths of molten tin for periods of from 4 to $400 \mathrm{hr}$ at temperatures ranging from 700 to $1,200{ }^{\circ} \mathrm{C}$. Also, in each bath was placed a specimen of 1/4-in.-diam wrought electron-beam melted niobium. ${ }^{3}$

The choice of the porous niobium bar was fortuitous because it provided two simultaneous experiments. First, by capillary action the molten tin was drawn up to fill all of the interstices in the niobium; thus the upper part of the bar represented conditions in the system where the amount of tin was limited. Second, the bottom of the specimen and the surfaces of both the porous bar and the wrought rod represented the tin-rich side of the

2 NBS spectrochemical analysis indicated the following impurity elements: $0.01-0.1 \% \mathrm{Fe}, \mathrm{Si} ; 0.001-0.01 \% \mathrm{Al}, \mathrm{Ca}, \mathrm{Cr}, \mathrm{Cu}, \mathrm{Mg}, \mathrm{Ni}$; less than $0.001 \% \mathrm{Ag}, \mathrm{B}$ $\mathrm{Mn}, \mathrm{Pb}, \mathrm{Pt}, \mathrm{Ta}, \mathrm{Ti}$.

3 NBS spectrochemical analysis indicated the following impurity elements: $0.01-0.1 \%$ none; $0.001-0.01 \% \mathrm{Cr}, \mathrm{Fe}, \mathrm{Mg}$, Si; less than $0.001 \% \mathrm{Ag}, \mathrm{B}, \mathrm{Ca}, \mathrm{Cu}$ $\mathrm{Ni}, \mathrm{Pt}$. system. In addition to these diffusion specimens, other specimens were prepared by compressing and sintering mixed powders and by fusion of the components. All of the resulting structures were heterogeneous.

The metallographic study of these materials was greatly facilitated by the use of anodic oxidation techniques suggested by Dr. M. L. Picklesimer of the ORNL. This procedure is an adaptation of a method first used for the study of zirconium hydrides [5]. Application of this technique imparts distinctive colors to the various microconstituents. These colors are uniform for each constituent for a single specimen and anodizing condition, but can be varied considerably by changes in the anodizing conditions. To prevent confusion in phase identification, the anodizing must be accurately controlled.

To eliminate polemic discussion between different observers examining the same or different microsections, it was decided to standardize the anodization of the present group of specimens so that niobium metal assumes a "Light Beryl Blue" coloration. To avoid use of multiple names for similar colors, it was agreed that the colors obtained under these conditions best match the colors in the Maerz and Paul Dictionary of Color [6] as follows:

$\begin{array}{ll}\mathrm{Nb} & \text { Light Beryl Blue } \\ \mathrm{Nb}_{4} \mathrm{Sn} & \text { Calamine Blue } \\ \mathrm{Nb}_{3} \mathrm{Sn} & \text { Orient } \\ \mathrm{Nb}_{2} \mathrm{Sn} & \text { Purple Aster } \\ \mathrm{Nb}_{2} \mathrm{Sn}_{3} & \text { Burnt Sienna } \\ \mathrm{Sn} & \text { Chrome Lemon } \\ \text { Impurity } & \text { Wistaria }\end{array}$

Plate 33, E-1 Plate $33, \mathrm{~J}-2$

Plate $36, \mathrm{D}-11$ Plate $43, \mathrm{~J}-7$

Plate 5, F-12

Plate $9, \mathrm{~K}-2$

Plate $41, \mathrm{E}-8$

In order to verify the chemical compositions of the observed phases, numerous areas were subjected to microspot analysis on the NBS electron probe, a description of which is currently in preparation [7].

A number of the microstructures resulting from the reaction of powder mixtures of known composition are the subject of a concurrent quantitative metallographic analysis by means of a digital computer. These methods have recently been outlined by Moore, Wyman, and Joseph [8]. In this current work, color separation prints, showing each phase separately, are made from color photomicrographs, or alternately from color separation negatives made directly on the microscope. Each phase separation print is then scanned into the computer and analyzed for the total amount of that particular phase, the continuity or connectivity of the phase, and the mean free path for linear motion within the phase areas. Details of this effort will be described in another report. Some preliminary results of this quantitative metallographic study have been drawn upon in estimating the probable position of some of the phase boundaries indicated in this paper.

It may be of interest to note here that one such analysis was made on a color micrograph, furnished by Dr. Picklesimer, representing a selected "bad" section of a commercial $\mathrm{Nb}$ sheathed " $\mathrm{Nb}_{3} \mathrm{Sn}$ " powder process wire. This section had been given a minimal reaction treatment prior to showing poor electrical properties, but other sections of the same 
wire, given a more complete reaction, showed a normal superconducting quality. The "bad" area was found to contain 70 volume percent of the $\mathrm{Nb}_{3} \mathrm{Sn}$ phase, of which at least 99 percent is interconnected by one or more circuitous paths, at least within the area of the micrograph. However, the mean free path within the $\mathrm{Nb}_{3} \mathrm{Sn}$ phase, in a direction parallel to the axis of the wire, is only $0.027 \mathrm{~mm}$. These results appear to indicate that the existence of a threadlike continuous path of convoluted shape is not in itself sufficient to guarantee useful superconducting properties; it would rather appear highly desirable to obtain wires so processed as to maximize the proportion of $\mathrm{Nb}_{3} \mathrm{Sn}$ in the structure and produce a high level of simple linear connectivity between the particles of this phase.

\section{Results}

Due to the fact that these initial experiments were conducted for the purpose of simulating thermal treatments which had previously produced good superconductor wire, the subsequent observations must be considered from this viewpoint, that is, as but preliminary results.

The diffusion studies have shown that the niobium-rich side of the system quite readily forms the intermetallic compound $\mathrm{Nb}_{4} \mathrm{Sn}$, whereas the tinrich side of the system forms the compound $\mathrm{Nb}_{2} \mathrm{Sn}_{3}$.

Between these two compounds, one finds the compounds $\mathrm{Nb}_{3} \mathrm{Sn}$ and $\mathrm{Nb}_{2} \mathrm{Sn}$. Additionally, there is a eutectic between $\mathrm{Nb}_{2} \mathrm{Sn}_{3}$ and the Sn-rich terminal phase occuring at about $215^{\circ} \mathrm{C}$ and near 83 percent $t^{4}$ Sn.

\subsection{Nature of the $\mathrm{Nb}_{4} \mathrm{Sn}$ Phase}

Preliminary studies of the melting of a specimen previously identified as consisting predominantly of $\mathrm{Nb}_{4} \mathrm{Sn}$ revealed partial fusion at $1,950 \pm 50{ }^{\circ} \mathrm{C}$ as determined with an optical pyrometer. Due to thermal gradients in the specimen, some portions

${ }^{4}$ All percentages in this paper are atomic percentages. were probably somewhat hotter, and in such an area subsequent microscopic examination revealed dendritic structure interspersed with small amounts of eutectic structure (fig. 5).

These observations lead to the conclusion that the compound $\mathrm{Nb}_{4} \mathrm{Sn}$ melts congruently near $2,050{ }^{\circ} \mathrm{C}$ and that it forms a eutectic with the niobium terminal solid solution; the eutectic composition presumably is located near to that of the compound.

\subsection{Electron-Probe Microanalyzer Measurements}

The identification of the phases in the system was carried out primarily with the NBS electron-probe. After the specimens had been subjected to the anodic oxidation technique, the composition of each "color" was determined. The results are listed in table 1. Column 3 shows the actual probe results and their average, while column 4 shows the phase assigned to the color.

\subsection{Metallographic Evidence for a Continuous $\mathrm{Nb}_{3}$ Sn Filament}

In general, when a niobium block is immersed in molten tin and then slowly cooled from above $700{ }^{\circ} \mathrm{C}$ the surface becomes converted to $\mathrm{Nb}_{4} \mathrm{Sn}$, which gradually and uniformly penetrates the block. As the process continues, there is an irregular outward growth into the Sn. Upon cooling, the tin-rich areas of this zone transform to $\mathrm{Nb}_{3} \mathrm{Sn}$. Additionally, the tips of the fingerlike $\mathrm{Nb}_{3} \mathrm{Sn}$ areas show the $\mathrm{Nb}_{2} \mathrm{Sn}_{3}$ phases growing crystals into the molten tin. Also, discrete crystals of $\mathrm{Nb}_{2} \mathrm{Sn}_{3}$ can be observed dispersed in the last areas to freeze.

If a continuous "filament" of $\mathrm{Nb}_{3} \mathrm{Sn}$ is essential for superconductivity, conditions for its proper formation must be such that there are enough niobium particles in the mass to permit their surfaces to react, forming $\mathrm{Nb}_{3} \mathrm{Sn}$, and that these surface layers must form mutual contact in order to attain continuity throughout a wire length.

TABLE 1. Results obtained by means of electron-probe microanalysis

\begin{tabular}{|c|c|c|c|}
\hline Troatment & Color analyzed & Results (atomic percent Sn) & Phase \\
\hline $34 \mathrm{hr}$ at $1,200^{\circ} \mathrm{C}+\mathrm{W} \cdot \mathrm{Q} \ldots$ & $\begin{array}{l}\text { Calamine blue. } \\
\text { Impurity }\end{array}$ & $\begin{array}{l}22.3 ; 21.5 ; 19.4 ; 21.0 \rightarrow \mathrm{A} \nabla 21.0 \\
0(60-70 \text { Atomic percent } \mathrm{Nb})\end{array}$ & $\begin{array}{l}\mathrm{Nb}_{4} \mathrm{Sn} \\
\mathrm{Nb}_{2} \mathrm{~N}(?)\end{array}$ \\
\hline $8 \mathrm{hr}$ at $1,200^{\circ} \mathrm{C}+\mathrm{S} . \mathrm{C} \ldots$ & Eutectic in $\mathrm{Sn} \ldots$ & $83.6 ; 83.3 \rightarrow \mathrm{A} \mathrm{v} 83.4$ & \\
\hline $8 \mathrm{hr}$ at $1,000{ }^{\circ} \mathrm{C}+\mathrm{S} . \mathrm{C}$. (wire in tube) $\ldots$ & Offshore ncedles in Sn (fig. 10) .- & 22.6 & $\mathrm{Nb}_{4} \mathrm{Sn}$ \\
\hline $\begin{array}{l}\text { Reaction tube held at } 800^{\circ} \mathrm{C}+\mathrm{W} . \mathrm{Q} \text {. Nomi- } \\
\text { nal } 25 \% \mathrm{Sn} \text {. }\end{array}$ & Calamine blue (matrix) .. - & $17.0 ; 23.2 ; 24.4 ; 18.5 ; \rightarrow \mathrm{Av} 20.8 \ldots \ldots$ & $\mathrm{Nb}_{4} \mathrm{Sn}$ \\
\hline $32 \mathrm{hr}$ at $900{ }^{\circ} \mathrm{C}+\mathrm{S} \cdot \mathrm{C} \ldots$ & $\begin{array}{l}\text { Orient } \\
\text { Burnt sienna......... }\end{array}$ & $24.7 ; 28.5 ; 27.1 \rightarrow \mathrm{Av} 26.8 \ldots \ldots$ & $\begin{array}{l}\mathrm{Nb}_{3} \mathrm{Sn} \\
\mathrm{Nb}_{2} \mathrm{Sn}_{3}\end{array}$ \\
\hline $400 \mathrm{hr}$ at $750^{\circ} \mathrm{C}+\mathrm{S} . \mathrm{C} \ldots$ & $\begin{array}{l}\text { Orient } \\
\text { Burnt sienna }\end{array}$ & $\begin{array}{l}26.5 \\
59.0\end{array}$ & $\begin{array}{l}\mathrm{Nb}_{3} \mathrm{Sn} \\
\mathrm{Nb}_{2} \mathrm{Sn}_{3}\end{array}$ \\
\hline $200 \mathrm{hr}$ at $700{ }^{\circ} \mathrm{C}+\mathrm{S} . \mathrm{C}$. [Run (1)] & Burnt sienna & $60.4 ; 61.6 ; 61.0 ; 62.1 ; 59.7 \rightarrow \mathrm{Av} 61.0 \ldots$ & $\mathrm{Nb}_{2} \mathrm{Sn}_{3}$ \\
\hline $200 \mathrm{hr}$ at $700^{\circ} \mathrm{C}+\mathrm{S} . \mathrm{C} .[\mathrm{Run}(2)] \ldots$ & Burnt sienna & $59.3 ; 58.3 ; 60.5 ; 58.0 ; 60.5 \rightarrow \mathrm{A} \vee 59.3 \ldots \ldots$ & $\mathrm{Nb}_{2} \mathrm{Sn}_{3}$ \\
\hline $\begin{array}{l}\text { Reaction tube held at } 600{ }^{\circ} \mathrm{C}+\mathrm{S} . \mathrm{C} \text {. } \\
\text { Nominal } 35 \% \mathrm{Sn} \text {. }\end{array}$ & $\begin{array}{l}\text { Purple aster } \\
\text { Calamine blue (matrix) } \\
\text { Orient }\end{array}$ & $\begin{array}{l}29.9 ; 29.3 ; 29.2 ; 30.2 ; 32.3 \rightarrow \mathrm{Av} 30.2 \ldots \ldots \ldots \\
21.8 ; 21.1 ; 18.6 ; 19.5 \rightarrow \mathrm{A} \vee 20.6 \ldots \\
25.1\end{array}$ & $\begin{array}{l}\mathrm{Nb}_{2} \mathrm{Sn} \\
\mathrm{Nb}_{4} \mathrm{Sn} \\
\mathrm{Nb}_{3} \mathrm{Sn}\end{array}$ \\
\hline
\end{tabular}


The interiors of many of the porous bars were replete with examples of this action. However, the most striking example was one in which the periphery of a $1 / 4$-in.-diam rod specimen became united with the flat surface of a porous bar during a $16 \mathrm{hr}$ treatment at $1,200{ }^{\circ} \mathrm{C}$, with subsequent furnace cooling. In this specimen the tangential interface was mainly $\mathrm{Nb}_{3} \mathrm{Sn}$, with thin layers of underlying $\mathrm{Nb}_{4} \mathrm{Sn}$ on each of the niobium bodies (fig. 6). Progressing

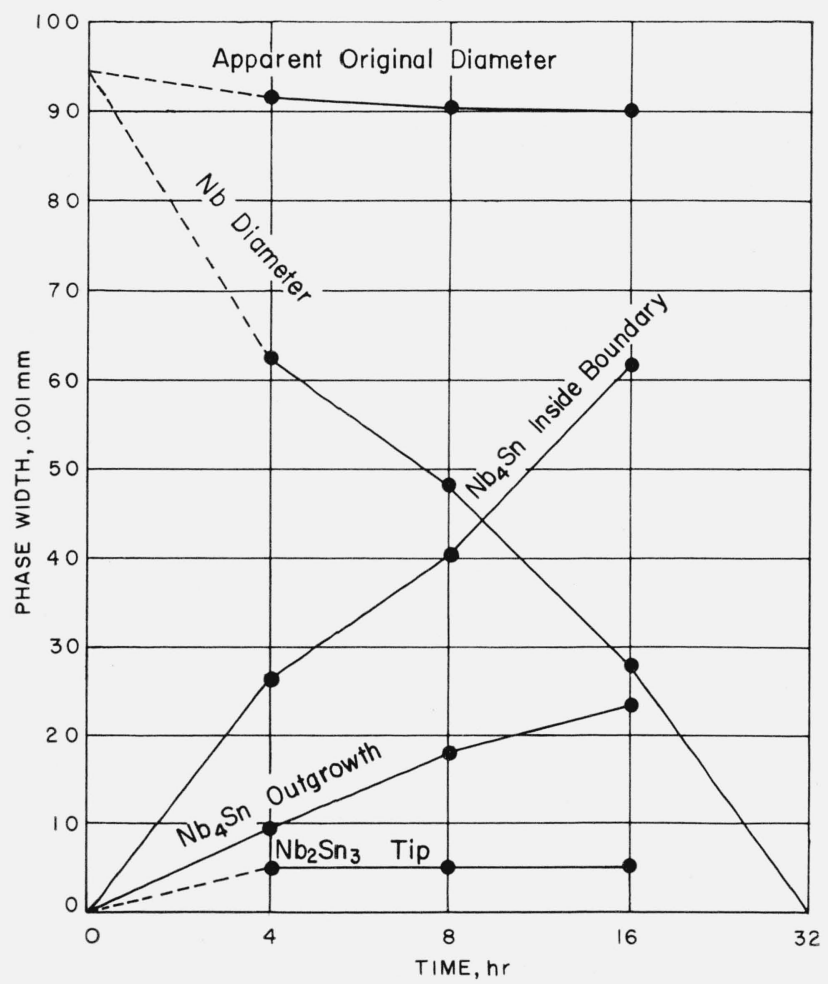

FIgURE 2. Growth of reaction layers on 0.004-in. niobium wires versus time in molten tin at $1,000{ }^{\circ} \mathrm{C}$ followed by furnace cooling.

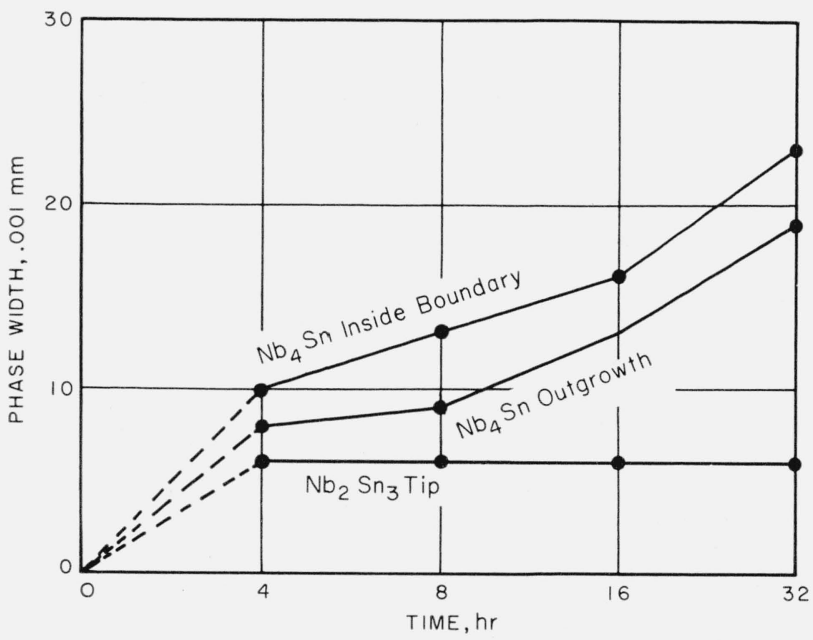

Figure 3. Reaction depths on the interior of the niobium shell versus time in molten tin at $1,000{ }^{\circ} \mathrm{C}$ followed by furnace cooling. away from the tangent area into the "V's" showing remaining $\mathrm{Sn}$, the layers on each niobium piece retained both the $\mathrm{Nb}_{4} \mathrm{Sn}$ and $\mathrm{Nb}_{3} \mathrm{Sn}$ and also revealed $\mathrm{Nb}_{2} \mathrm{Sn}_{3}$ needles forming on the $\mathrm{Nb}_{3} \mathrm{Sn}$ and growing into the $\mathrm{Sn}$.

\subsection{Reaction of Niobium Wires in a Bath of Tin at $1,000^{\circ} \mathrm{C}$}

In another set of experiments, small niobium wires were threaded into a 1/8-in.-I.D. niobium tube and the tube then filled with $\mathrm{Sn}$. These specimens were treated for periods of $4,8,16$, and $32 \mathrm{hr}$ at $1,000{ }^{\circ} \mathrm{C}$, the latter being water quenched, and the others furnace cooled.

The alloying in these specimens progressed in quite the same manner as that previously described. In addition, the $\mathrm{Nb}_{4} \mathrm{Sn}$ "grew" out beyond the limits of the original niobium wire area and in turn developed the $\mathrm{Nb}_{3} \mathrm{Sn}$ and $\mathrm{Nb}_{2} \mathrm{Sn}_{3}$ layers (fig. 7).

The 32-hr water quenched specimen revealed a completely new condition because from 43 wires originally within the tube, there remained but one very small speck of niobium surrounded by a few islands of $\mathrm{Nb}_{4} \mathrm{Sn}$.

Rough measurements were made of the progress of the reaction layers in this series of treatments, the results being shown graphically in figure 2 . Similar measurements of reaction depths on the interior of the niobium tube are shown in figure 3 . The extent of the $\mathrm{Nb}_{3} \mathrm{Sn}$ layer could not be measured due to the quite irregular nature of the surface. However, this phase was observed to be present in the 4-, 8-, and 16-hr specimens as a narrow zone of variable thickness lying between the overlying $\mathrm{Nb}_{2} \mathrm{Sn}_{3}$ crystals and the underlying $\mathrm{Nb}_{4} \mathrm{Sn}$.

This wires-in-tube experiment points out the possibility of a new means of fabricating the Nb-Sn complex in such manner as to more completely insure a continuity of the $\mathrm{Nb}_{3} \mathrm{Sn}$ phase throughout the entire length of the wire.

\subsection{Diffusion Studies}

The diffusion specimen which was water quenched after $32 \mathrm{hr}$ at $1,200{ }^{\circ} \mathrm{C}$ (fig. 9) showed quite large amounts of $\mathrm{Nb}_{4} \mathrm{Sn}$ in the reaction zones, together with infrequent crystal tips of $\mathrm{Nb}_{2} \mathrm{Sn}_{3}$, but no $\mathrm{Nb}_{3} \mathrm{Sn}$ or $\mathrm{Nb}_{2} \mathrm{Sn}$. In contrast to this, the furnace cooled specimen had a reaction zone predominantly $\mathrm{Nb}_{3} \mathrm{Sn}$ with frequent $\mathrm{Nb}_{2} \mathrm{Sn}_{3}$ tips (fig. 8).

In most of the slow-cooled specimens from the initial 700 to $1,200{ }^{\circ} \mathrm{C}$ diffusion series there was a distinct but very narrow band of precipitate in the tin at a short distance from the $\mathrm{Nb}-\mathrm{Sn}$ reaction surface. At the higher treatment temperatures, distinct needles were observed in this band. From their position, these needles were at first expected to be a high tin phase, but they were subsequently identified by color comparison in normal and in polarized light, and by electron probe analysis, as being composed of $\mathrm{Nb}_{4} \mathrm{Sn}$ (fig. 10).

Previous mention was made of the observation that the water-quenched wire-in-tube specimen 
treated $32 \mathrm{hr}$ at $1,000{ }^{\circ} \mathrm{C}$ revealed only a trace of niobium together with small particles of $\mathrm{Nb}_{4} \mathrm{Sn}$. $\mathrm{No} \mathrm{Nb}_{3} \mathrm{Sn}$ was in evidence. Similariy, in the diffusion series held at $1,000{ }^{\circ} \mathrm{C}$, the $4-, 8-$, and $16-\mathrm{hr}$ slow-cooled specimens displayed islands of $\mathrm{Nb}_{3} \mathrm{Sn}$ and a bit of $\mathrm{Nb}_{2} \mathrm{Sn}_{3}$ in the $\mathrm{Nb}_{4} \mathrm{Sn}$ bands (fig. 8).

After studying the microsections from the various diffusion experiments, the fact became evident that the $\mathrm{Nb}_{3} \mathrm{Sn}$ phase can form quite readily from the $\mathrm{Nb}_{4} \mathrm{Sn}$ phase on slow cooling. Quenched specimens retain only the $\mathrm{Nb}_{4} \mathrm{Sn}$.

As compared with the long diffusion times required to convert niobium particles or wires to $\mathrm{Nb}_{4} \mathrm{Sn}$, the conversion of $\mathrm{Nb}_{4} \mathrm{Sn}$ to $\mathrm{Nb}_{3} \mathrm{Sn}$ appears to proceed too rapidly to allow the diffusion of an additional 5 percent of tin into the converted areas. Such a difference might be expected if the $\mathrm{Nb}_{4} \mathrm{Sn}$ phase dissolves excess tin, and thus approaches the $\mathrm{Nb}_{3} \mathrm{Sn}$ composition.

Evidence of width for the $\mathrm{Nb}_{4} \mathrm{Sn}$ phase was obtained by making electron-probe traverses across $\mathrm{Nb}_{4} \mathrm{Sn}$ areas on a specimen quenched from $1,200{ }^{\circ} \mathrm{C}$. The analytical values so obtained indicated a composition gradient of about 6 percent within the $\mathrm{Nb}_{4} \mathrm{Sn}$ areas. This would place the tentative limits of the $\mathrm{Nb}_{4} \mathrm{Sn}$ phase region at 17 and 23 percent at $1,200{ }^{\circ} \mathrm{C}$, and confirm that only a small amount of additional tin is required for conversion to the $\mathrm{Nb}_{3} \mathrm{Sn}$ phase.

\subsection{Thermal Analysis}

A specimen of nominal " $\mathrm{Nb}_{2} \mathrm{Sn}_{3}$ " composition was subjected to thermal analysis (direct time versus temperature). This powder mixture had been pressed at $150{ }^{\circ} \mathrm{C}$ and 100,000 psi prior to loading into the furnace. The sample gave reproducible thermal arrests on three separate but continuous heating and cooling runs at $3^{\circ} \mathrm{C} / \mathrm{min}$. Two thermal arrests on cooling occurred at $922 \pm 5{ }^{\circ} \mathrm{C}$ and at $863 \pm 5{ }^{\circ} \mathrm{C}$ and were easily detected from the temperature recording. The sample was later prepared for metallographic observation and it exhibited the $\mathrm{Nb}, \mathrm{Nb}_{4} \mathrm{Sn}, \mathrm{Nb}_{3} \mathrm{Sn}, \mathrm{Nb}_{2} \mathrm{Sn}_{3}$ phases in an excess of Sn (figs. 11, 12).

Additional thermal analyses were run on pressed pellets of " $\mathrm{Nb}_{3} \mathrm{Sn}$ " composition, but, in general, no strong arrests were noted. However, in one instance in which the sample was being held at a steady temperature near $1,150{ }^{\circ} \mathrm{C}$, the furnace winding burned out and consequently the specimen cooled more quickly than the usual rate. During this cooling, the temperature record showed a definite arrest at $743{ }^{\circ} \mathrm{C}$.

TABLE 2. Results of thermal analysis

\begin{tabular}{|c|c|c|c|}
\hline Sample & Cooling rate & \multicolumn{2}{|c|}{ Arrest Temperature } \\
\hline 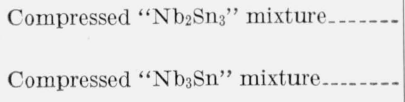 & $3^{\circ} \mathrm{C} / \mathrm{min}$ & $\begin{array}{l}917{ }^{\circ} \mathrm{C} \\
927 \\
924 \\
743\end{array}$ & $\begin{array}{l}858^{\circ} \mathrm{C} \\
867 \\
867\end{array}$ \\
\hline
\end{tabular}

The thermal analysis data have been interpreted to assign the $863^{\circ} \mathrm{C}$ temperature as the peritectic temperature of the $\mathrm{Nb}_{2} \mathrm{Sn}_{3}$ compound and the $922{ }^{\circ} \mathrm{C}$ temperature as the liquidus for this composi- tion. The $743{ }^{\circ} \mathrm{C}$ arrest on a quick cool is probably near the peritectoid temperature of the $\mathrm{Nb}_{3} \mathrm{Sn}$ compound. The results are shown in table 2.

\subsection{High-Temperature Metallography}

In a further attempt to reveal the reactions occurring in this system, a microsection containing a wide vein of $\mathrm{Nb}_{2} \mathrm{Sn}_{3}$ with side veins of $\mathrm{Nb}_{4} \mathrm{Sn}$ and $\mathrm{Nb}_{3} \mathrm{Sn}$ was removed from the diffusion specimen treated for $200 \mathrm{hr}$ at $700{ }^{\circ} \mathrm{C}$. This section was mounted in the high-temperature stage of a metallurgical microscope in a purified argon atmosphere and kept under observation during a 3 -hr heating to an indicated $930{ }^{\circ} \mathrm{C}$.

No significant changes were observed up to 450 ${ }^{\circ} \mathrm{C}$. However, from this temperature up to $693{ }^{\circ} \mathrm{C}$ there were grain-boundary changes in the $\mathrm{Nb}_{2} \mathrm{Sn}_{3}$, and some changes in the $\mathrm{Nb}_{4} \mathrm{Sn}$ and $\mathrm{Nb}_{3} \mathrm{Sn}$ side veins. At $693{ }^{\circ} \mathrm{C}$ the narrow band $\left(\mathrm{Nb}_{3} \mathrm{Sn}+\mathrm{Nb}_{4} \mathrm{Sn}\right)$ between the $\mathrm{Nb}_{2} \mathrm{Sn}_{3}$ and the niobium appeared to be more clearly defined and slightly wider. Between 693 and $735^{\circ} \mathrm{C}$ a new phase believed to be $\mathrm{Nb}_{3} \mathrm{Sn}$ had made its appearance at the $\mathrm{Nb}-\mathrm{Nb}_{2} \mathrm{Sn}_{3}$ interface and had grown slightly into both phases. During the course of the heating, the noble-metal thermocouple, located adjacent to the specimen, indicated a brief arrest at $863{ }^{\circ} \mathrm{C}$. As heating continued, this new phase grew until, at $930{ }^{\circ} \mathrm{C}$, it had gradually covered the entire field of view.

At this point, the specimen was given a "gasquench," resulting in a fairly rapid drop in temperature, probably of the order of $400{ }^{\circ} \mathrm{C}$ the first minute.

Microscopic examination of the specimen after removal from the furnace failed to provide further information, due to surface roughness. Also, the usual anodizing procedure failed to give response, As a consequence, the specimen was remounted, very lightly repolished, and then anodized. The structure then revealed a mixture of $\mathrm{Nb}_{4} \mathrm{Sn}$ and $\mathrm{Nb}_{3} \mathrm{Sn}$ scattered through the niobium grains, with the original vein of solid $\mathrm{Nb}_{2} \mathrm{Sn}_{3}$ terminating as a heavily voided area of dendritic appearance.

\subsection{General Nature of the System}

During the course of these investigations, several generalities have evolved which indicate the type of system under study, as well as some of the difficulties to be anticipated in finally determining the facts concerning the several reactions and their rates. For example, there is considerable evidence that the formation of $\mathrm{Nb}_{3} \mathrm{Sn}, \mathrm{Nb}_{2} \mathrm{Sn}$, and $\mathrm{Nb}_{2} \mathrm{Sn}_{3}$ is a function of the rate of cooling from temperatures above the decomposition temperatures for these compounds. As a consequence, it is essential to the controlled formation of $\mathrm{Nb}_{3} \mathrm{Sn}$ that the characteristics of the decomposition reactions be determined.

In this connection, accumulated observations made during the course of these investigations give some indications as to the nature of these reactions. Thus, the unexpected and repeated observance of three or four phases after long-term thermal treatments clearly reveals the sluggishness of some of these reactions. Furthermore, this offers a significant 
reason for the observation that the reaction horizontals are difficult to detect by thermal analysis.

The original series of diffusion experiments revealed limited ranges of stability for $\mathrm{Nb}_{2} \mathrm{Sn}_{3}, \mathrm{Nb}_{2} \mathrm{Sn}$, and $\mathrm{Nb}_{3} \mathrm{Sn}$. The $\mathrm{Nb}_{2} \mathrm{Sn}_{3}$ phase, appearing as a band at the reaction interface, is much more abundant at $700{ }^{\circ} \mathrm{C}$ than at higher temperatures. In the range from 750 to $900{ }^{\circ} \mathrm{C}$ this layer becomes thinner and discontinuous. In slowly cooled specimens from the higher temperatures, $\mathrm{Nb}_{2} \mathrm{Sn}_{3}$ is usually found only at the tips of $\mathrm{Nb}_{3} \mathrm{Sn}$ protuberances extending into the tin-rich liquid, or in pockets where tin has been trapped between niobium particles. These structures can be explained if $\mathrm{Nb}_{2} \mathrm{Sn}_{3}$ decomposes thermally at some temperature below $900{ }^{\circ} \mathrm{C}$, and if, at lower temperatures, it reacts with niobium or $\mathrm{Nb}_{4} \mathrm{Sn}$ to vield $\mathrm{Nb}_{3} \mathrm{Sn}$ and $\mathrm{Nb}_{2} \mathrm{Sn}$.

The $\mathrm{Nb}_{3} \mathrm{Sn}$ phase, in turn, while generally present in significant amounts in the reaction layers of slowly cooled specimens, was essentially absent from all of the quenched specimens. Specimens which originally contained identified $\mathrm{Nb}_{3} \mathrm{Sn}$, including a special powder mixture prepared for this purpose, contained extensive areas of $\mathrm{Nb}_{3} \mathrm{Sn}$ after heating to temperatures as high as $1,000{ }^{\circ} \mathrm{C}$ and quenching from $800{ }^{\circ} \mathrm{C}$ or higher. These observations appear to contain numerous contradictions and leave the true decomposition temperature of $\mathrm{Nb}_{3} \mathrm{Sn}$ most uncertain.

\subsection{Reacted Stoichiometric Mixtures of Niobium and Tin}

In an effort to fix more firmly the position of the lines defining the interactions of $\mathrm{Nb}_{4} \mathrm{Sn}, \mathrm{Nb}_{3} \mathrm{Sn}$, $\mathrm{Nb}_{2} \mathrm{Sn}$, and $\mathrm{Nb}_{2} \mathrm{Sn}_{3}$, a series of specimens of accurately predetermined composition were prepared for quantitative metallographic measurement by the digital computer [8]. Mixtures of niobium and tin powders, covering the range from 10 to 60 percent tin, were hot pressed into pellets and then pressed into niobium tubes. The mixtures were reacted at $1,000{ }^{\circ} \mathrm{C}$, cooled to low temperatures to establish a new equilibrium, and then water quenched. Preliminary examinations of these series may be summarized as follows:

Specimens water quenched from $1,000{ }^{\circ} \mathrm{C}$ contained only niobium, $\mathrm{Nb}_{4} \mathrm{Sn}$, and a quenched liquid, not $\mathrm{Nb}_{2} \mathrm{Sn}_{3}$ crystals. The quenched liquid, by a preliminary material balance, appears to lie closer to 50 than to 60 percent $\mathrm{Sn}$.

Specimens quenched from $800{ }^{\circ} \mathrm{C}$ were originally similar to the $1,000{ }^{\circ} \mathrm{C}$ specimens, with a few very small particles of $\mathrm{Nb}_{3} \mathrm{Sn}$ mixed in with the particles of high tin material. Critical examination of the specimen containing 60 percent tin, made some weeks after quenching, showed large amounts of $\mathrm{Nb}_{2} \mathrm{Sn}_{3}$, which apparently was stable at $800{ }^{\circ} \mathrm{C}$. In the lower tin ranges, residual particles of $\mathrm{Nb}_{2} \mathrm{Sn}_{3}$ or quenched liquid apparently had reacted with $\mathrm{Nb}_{4} \mathrm{Sn}$ and niobium to form additional particles of $\mathrm{Nb}_{3} \mathrm{Sn}$.

Specimens quenched after $21 \mathrm{hr}$ at $700{ }^{\circ} \mathrm{C}$ all showed considerable amounts of $\mathrm{Nb}_{3} \mathrm{Sn}$, which, however, had not yet replaced $\mathrm{Nb}_{4} \mathrm{Sn}$ as the con- tinuous phase. Thus these specimens were reacted below the decomposition temperature of $\mathrm{Nb}_{3} \mathrm{Sn}$, but as the reaction was proceeding slowly, it may be presumed that $700{ }^{\circ} \mathrm{C}$ is only slightly below this critical temperature.

Specimens slowly cooled after $18 \mathrm{hr}$ at $600{ }^{\circ} \mathrm{C}$ showed both $\mathrm{Nb}_{2} \mathrm{Sn}$ and $\mathrm{Nb}_{3} \mathrm{Sn}$ in a matrix of $\mathrm{Nb}_{4} \mathrm{Sn}$. There were also a few particles of unreacted niobium. The identity of the $\mathrm{Nb}_{2} \mathrm{Sn}$ phase was confirmed in this group of specimens by means of the electronprobe microanalyzer. These results are summarized in table 3.

\section{TABLE 3. Phases observed in reacted powder mixtures}

Mixtures pressed, reacted at $1,00{ }^{\circ} \mathrm{C}$, and finished by final reaction listed

\begin{tabular}{|c|c|c|c|c|c|c|c|}
\hline \multicolumn{2}{|c|}{ Fina! treatment } & \multirow{2}{*}{$\frac{\mathrm{Nb}}{\mathrm{L} \text { blue }}$} & \multirow{2}{*}{$\frac{\mathrm{Nb}_{4} \mathrm{Sn}}{\mathrm{C} . \text { blue }}$} & \multirow{2}{*}{$\mathrm{Nb}_{3} \mathrm{Sn}$} & \multirow{2}{*}{$\mathrm{Nb}_{\text {Aster }}$} & \multirow{2}{*}{$\frac{\mathrm{Nb}_{2} \mathrm{Sn}_{3}}{\text { Sienna }}$} & \multirow{2}{*}{$\begin{array}{l}\text { Quenched } \\
\text { liquid }\end{array}$} \\
\hline Temp. & Cooled & & & & & & \\
\hline${ }^{\circ} \mathrm{C}$ & & & & & & & \\
\hline $1,000 \ldots$ & WQ & + & ++ & (n) & - & - & t \\
\hline $800 \ldots$ & WQ & + & ++ & (n) & - & + & - \\
\hline 740 & $\mathrm{Q}(1)$ & + & + & tr & - & + & - \\
\hline 715 & $Q(1)$ & + & + & ++ & - & $\mathrm{tr}$ & - \\
\hline 700 & WQ & + & + & + & - & + & - \\
\hline 680 & $\mathrm{Q}(1)$ & + & + & + & + & $\mathrm{tr}$ & - \\
\hline $600 \ldots$ & F.C. & + & + & + & + & + & - \\
\hline
\end{tabular}

(1) Single small pieces of a thermal analysis specimen at $75 \% \mathrm{Nb}, 25 \% \mathrm{Sn}$, water quenched. All others are summation of observations on 9 compositions. (n) Some specimens, particulary these near $35 \%$ Sn, showed a few small spots of $\mathrm{Nb}_{3} \mathrm{Sn}$ when first examined. Over several weeks, additional particles of $\mathrm{Nb}_{3} \mathrm{Sn}$ grew at the interfaces between $\mathrm{Nb}_{4} \mathrm{Sn}$ and $\mathrm{Nb}_{2} \mathrm{Sn}_{3}$.

+ Indicates presence.

++ Indicates presence in large amount.

tr Indicates trace.

- Indicates absence.

Thus, the decomposition temperature of $\mathrm{Nb}_{2} \mathrm{Sn}_{3}$ lies between 800 and $1,000{ }^{\circ} \mathrm{C}$, and must of necessity be of the peritectic form, while the decomposition of the desired $\mathrm{Nb}_{3} \mathrm{Sn}$ phase lies below $800{ }^{\circ} \mathrm{C}$ and can be associated with earlier evidences of changes near $730{ }^{\circ} \mathrm{C}$. The reaction observed in this temperature range is now seen to be due to the peritectoid decomposition of $\mathrm{Nb}_{3} \mathrm{Sn}$ in to $\mathrm{Nb}_{4} \mathrm{Sn}$ and $\mathrm{Nb}_{2} \mathrm{Sn}_{3}$, and not to a monotectic at higher tin composition as originally presumed by Savitskii et al.

One additional observation on the pressed powder specimens is significant to the present discussion. After the specimens quenched from $800{ }^{\circ} \mathrm{C}$ had been stored for some weeks, all of the residual niobium particles could be seen to contain a barely resolvable Widmanstatten structure covering all of the central areas and extending to within a short distance (around $0.002 \mathrm{~mm}$ ) from the surface (which is generaliy in contact with $\mathrm{Nb}_{4} \mathrm{Sn}$ ). This structure indicates that Savitskii's estimate of relatively extensive tin solubility in the terminal niobium phase should be accepted for the high-temperature range. However, the solubility limit must retreat at lower temperatures in the manner of a typical precipitation hardening solution.

\subsection{Friability in the Observed Intermetallic Phases}

The hardness values for the three identifiable compounds have not as yet been determined. However, it was initially recognized by the early experimenters with $\mathrm{Nb}_{3} \mathrm{Sn}$ that this compound was extremely brittle[1]. In fact, this brittleness is 
highly detrimental to the processing of the wire into magnet windings because the slightest bending of a heat-treated wire will fracture the superconducting core. As a consequence, heat treatment must follow the coil forming.

Metallographic examination fully confirms this occurrence for it may be noted that areas of $\mathrm{Nb}_{3} \mathrm{Sn}$ frequently abound with cracks. In addition to this, it was also noted that too much haste in specimen grinding resulted in the chipping out of $\mathrm{Nb}_{3} \mathrm{Sn}$ areas.

The $\mathrm{Nb}_{2} \mathrm{Sn}_{3}$ phase exhibits a rather unusual friability. This phase is usually observed to form by outward growth into areas of the Sn-rich phase. In addition, individual crystals may be found in the $\mathrm{Sn}$, adjacent to a reaction interface. The unusual feature to be noted is that both the "growing" crystals and the "free" crystals usually display severe cracking.

In contrast to these observations, the $\mathrm{Nb}_{4} \mathrm{Sn}$ phase does not exhibit cracking, nor does it readily chip out during metallographic specimen preparation.

\subsection{Impurity Inclusion in the Porous Niobium Bar}

In addition to the phases so far identified, several of the diffusion couples have shown, in the porous niobium bar only, a streamerlike structure. These streamers appear as a wistaria color (fig. 9) when subjected to the anodic oxidation technique.
An attempt to determine the composition of these streamers was made by means of the electronprobe. The results showed that they contained no tin and about 60 to 70 percent $\mathrm{Nb}$. Based on these data, it is felt that the streamers are extraneous to the binary system Nb-Sn. Furthermore, the wrought electron-beam melted niobium rod never showed these streamers or a phase of a color approximating wistaria. It is suggested that the probable identity of the streamers may be $\mathrm{Nb}_{2} \mathrm{~N}$.

As the result of the investigations of the $\mathrm{Nb}-\mathrm{Sn}$ binary system thus far conducted, the evidence clearly shows that the prior constitutional diagram is most incomplete. The tentative diagram shown in figure 4 is offered in its place as indicating the salient features of the system as shown by the investigations carried out to date.

\section{Discussion}

The present investigations have revealed several factors which are pertinent to any attempt to understand the physical metallurgy of the composite $\mathrm{Nb}$ - " $\mathrm{Nb}_{3} \mathrm{Sn}$ " wires which have displayed such outstanding superconducting properties. Furthermore, the complete story of the physical metallurgy is essential to the process metallurgist in order that he may best fabricate this material, and to the physicist as a basis for further theoretical studies of superconductivity.

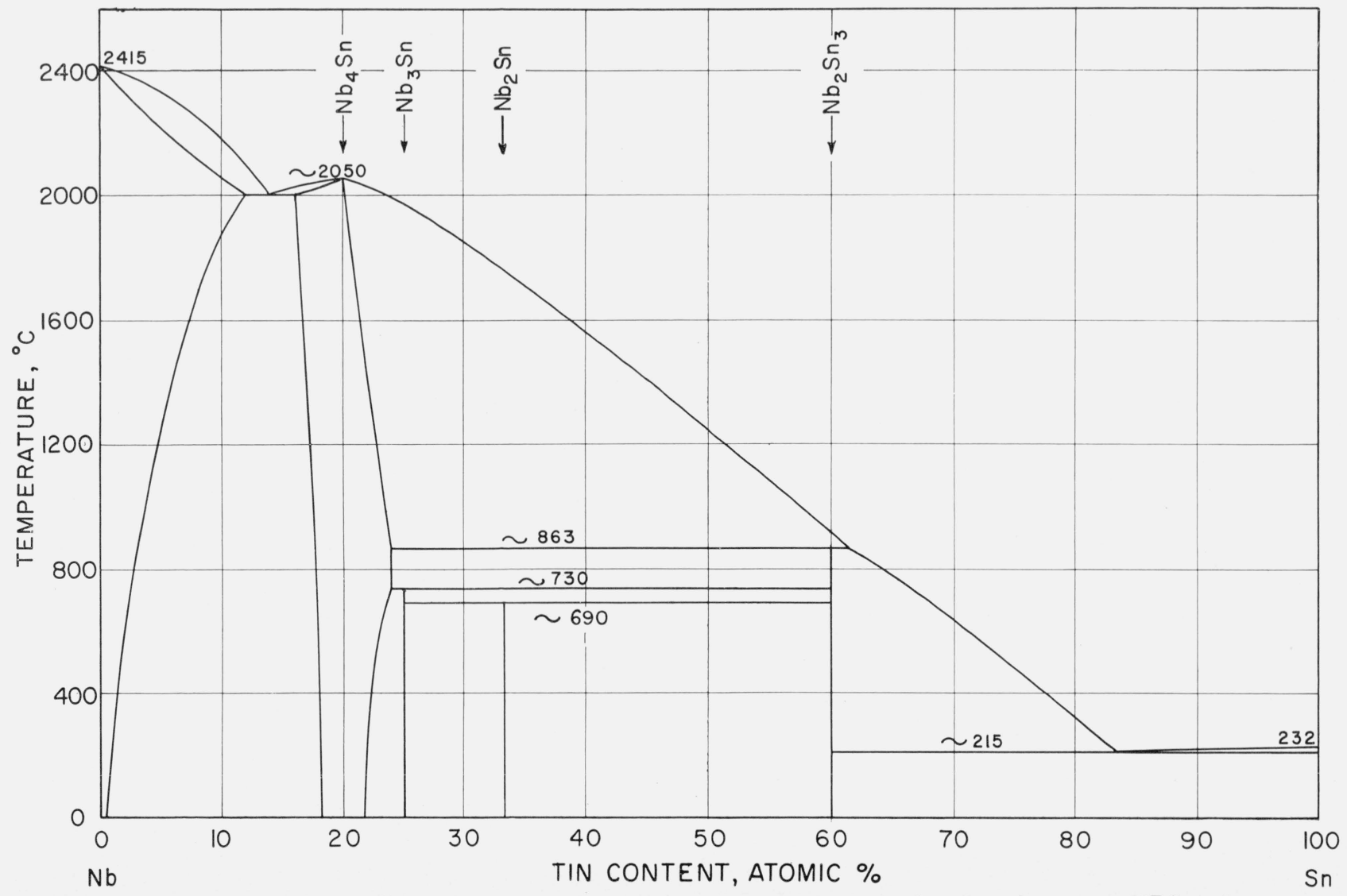

Figure 4. Proposed tentative constitution diagram for the niobium-tin system based on the present NBS study. 
Niobium and tin react quite readily to form $\mathrm{Nb}_{4} \mathrm{Sn}$ at temperatures far below the melting point of the compound. On the other hand, practical experience has shown that the direct formation of the compound $\mathrm{Nb}_{3} \mathrm{Sn}$ either by diffusion of tin into solid niobium or by fusion of the components, seldom meets with material success.

In diffusion experiments near $800{ }^{\circ} \mathrm{C}, \quad \mathrm{Nb}_{2} \mathrm{Sn}_{3}$ appears to form quite readily in layers at the $\mathrm{Nb}_{4^{-}}$ $\mathrm{Sn}-\mathrm{Sn}$ interface, with crystals of $\mathrm{Nb}_{2} \mathrm{Sn}_{3}$ growing out into the tin and occasionally becoming detached. By contrast, the $\mathrm{Nb}_{3} \mathrm{Sn}$ phase appears only as much thinner layers and is usually discontinuous.

This configuration can be expected when one realizes that the $\mathrm{Nb}_{3} \mathrm{Sn}$ phase itself is not stable in this temperature range, and hence that the observed layer is found, on cooling, only in those areas where the composition is very close to 25 percent tin.

The extent of the areas which can transform directly to $\mathrm{Nb}_{3} \mathrm{Sn}$ on cooling can be increased by control of the configuration of the niobium particles and of the degree to which the reaction with tin is allowed to progress. This control must prevent either excessive reaction with tin, which will produce reaction layers predominantly of $\mathrm{Nb}_{2} \mathrm{Sn}_{3}$, or excessive reaction of niobium, which will produce mainly $\mathrm{Nb}_{4} \mathrm{Sn}$. A diffusion reaction at or below $700{ }^{\circ} \mathrm{C}$ should avoid these undesirable reactions, but probably would require a very much longer reaction time than would be acceptable.

The problem of producing a homogeneous core of $\mathrm{Nb}_{3} \mathrm{Sn}$, either by fusion methods or by complete interaction of niobium and tin powders, involves first forming a mixture of $\mathrm{Nb}_{4} \mathrm{Sn}$ and $\mathrm{Nb}_{2} \mathrm{Sn}_{3}$, followed by a peritectoid reaction between these products to form the $\mathrm{Nb}_{3} \mathrm{Sn}$.

The application of these phenomena to practical wire fabrication could take two distinct forms. If a continuous network of $\mathrm{Nb}_{3} \mathrm{Sn}$ is sufficient to meet the requirements for superconductivity, niobium particles, preferably of elongated or fine niobium wires, may in effect be cemented together by a continuous film of $\mathrm{Nb}_{3} \mathrm{Sn}$. If the reaction is operated near $1,000{ }^{\circ} \mathrm{C}$, the reaction time must be closely controlled in order to stop the reaction when material containing 25 percent $\mathrm{Sn}$ is most abundant. The amount of tin to be used in this case will be dictated in part by packing considerations, and might be well below 25 percent if much of the niobium is to remain unreacted.

If homogeneous $\mathrm{Nb}_{3} \mathrm{Sn}$ must be produced, a mixture containing 25 percent tin may be reacted at or above $1,000{ }^{\circ} \mathrm{C}$ until the core is completely converted to $\mathrm{Nb}_{4} \mathrm{Sn}$ and residual liquid. This mixture may then subsequently be annealed in the range 600 to $700{ }^{\circ} \mathrm{C}$ until the peritectoid conversion to $\mathrm{Nb}_{3} \mathrm{Sn}$ is complete.

Probably the most significant practical result of this investigation will be to clarify the fact that the desired $\mathrm{Nb}_{3} \mathrm{Sn}$ phase does not exist at the reaction temperatures normally employed in producing the superconducting complex. Thus, regardless of other details of fabrication, the attainment of a satisfactory superconducting structure will be directly associated with the rate of cooling from the reaction temperature; and, specifically, with the time that the material remains in the 600 to $700{ }^{\circ} \mathrm{C}$ range.

\section{Conclusions}

Current investigations of $\mathrm{Nb}-\mathrm{Sn}$ superconducting materials have shown thus far that the $\mathrm{Nb}-\mathrm{Sn}$ binary alloy system is much more complicated than had previously been assumed. A new constitutional diagram is proposed predicated from the results thus far obtained in the current investigations.

The intermetallic compound $\mathrm{Nb}_{3} \mathrm{Sn}$, which appears to be the desirable constituent for superconducting purposes, occurs between the compounds $\mathrm{Nb}_{4} \mathrm{Sn}$ and $\mathrm{Nb}_{2} \mathrm{Sn}_{3}$, which are stable to considerably higher temperatures. At lower temperatures, the system is further complicated by the formation of $\mathrm{Nb}_{2} \mathrm{Sn}$.

This seriously complicates the problem of attaining either a continuous body of homogeneous $\mathrm{Nb}_{3} \mathrm{Sn}$ throughout a conductor, or of obtaining a controlled type of heterogeneous structure which will give a continuously interconnected network of the superconductor. The successful preparation of either type of structure will require critical control of the preparation and heat treatment of the material in order to overcome the inherent difficulty in forming the desired phase.

The previously described investigations were instigated and were conducted under the auspices of the Cryogenic Engineering Section of the NBS Boulder Laboratories, R. B. Scott, Chief. The advice and assistance rendered by Messrs. Arp, Corruccini, and Kropschot of this group is most deeply appreciated. Thanks are also extended to Messrs. C. A. Owens, W. J. Hall, and B. T. Sanderson of this laboratory for the preparation of specimens.

\section{References}

[1] J. E. Kunzler, E. Buehler, F. S. L. Hso, and J. H. Wernick, Superconductivity in $\mathrm{Nb}_{3} \mathrm{Sn}$ at high current density in a magnetic field of $88 \mathrm{Kgauss}$, Phys. Rev. Letters 6, $89,(1961)$

[2] V. D. Arp, R. H. Kropschot, and J. H. Wilson, Superconductivity of $\mathrm{Nb}_{3} \mathrm{Sn}$ in pulsed fields of 185 kilogauss, Phys. Rev. Letters 6 (9), 452, (1961).

[3] B. T. Matthias, T. H. Geballe, S. Geller, and E. Corenzwit, Superconductivity of $\mathrm{Nb}_{3} \mathrm{Sn}$, Phys. Rev. 95, 1435, (1954).

[4] E. M. Savitskii, M. I. Agafona, and V. V. Baron, The structure and properties of niobium-tin alloys, Izvest. Akad. Nauk S.S.S.R. Met. i Toplivo (Teklin) 1959 (5) 138-141 (in Russian).

[5] M. L. Picklesimer, Anodizing as a metallographic technique for zirconium base alloys, United States Atomic Energy Commission ORNL-2296, 13pp., (1957).

[6] A. Maerz and M. R. Paul, Dictionary of Color, MeGrawHill Book Company, Inc., New York, New York (1930).

[7] J. R. Cuthill, L. L. Wyman, and H. Yakowitz, Metallurgical microanalysis by means of the electron probe, (in preparation).

[8] G. A. Moore, L. L. Wyman, and H. M. Joseph, Comments on the possibilities of performing quantitative metallographic analysis with a digital computer. Ch. from Quantitative Metallography, F. N. Rhines Ed. McGraw-Hill Co., in Press. 


\section{LEGEND}

PHASE DESIGNATION ${ }^{+}$LOCATION COLOR

$\mathrm{Nb} \quad$ Light Beryl Blue Plate 33;E-I

$\mathrm{Nb}_{4} \mathrm{Sn} \quad$ Calamine Blue Plate $33 ; \mathrm{J}-2$

$\mathrm{Nb}_{3} \mathrm{Sn} \quad$ Orient

Plate $36 ; \mathrm{D}-11$

$\mathrm{Nb}_{2} \mathrm{Sn} \quad$ Purple Aster Plate 43;J-7

$\mathrm{Nb}_{2} \mathrm{Sn}_{3} \quad$ Burnt Sienna Plate $5 ; \mathrm{F}-12$

Sn

Chrome Lemon Plate 9; K-2

Impurity Wistaria

Plate $41 ; E-8$

+See ref. 6 


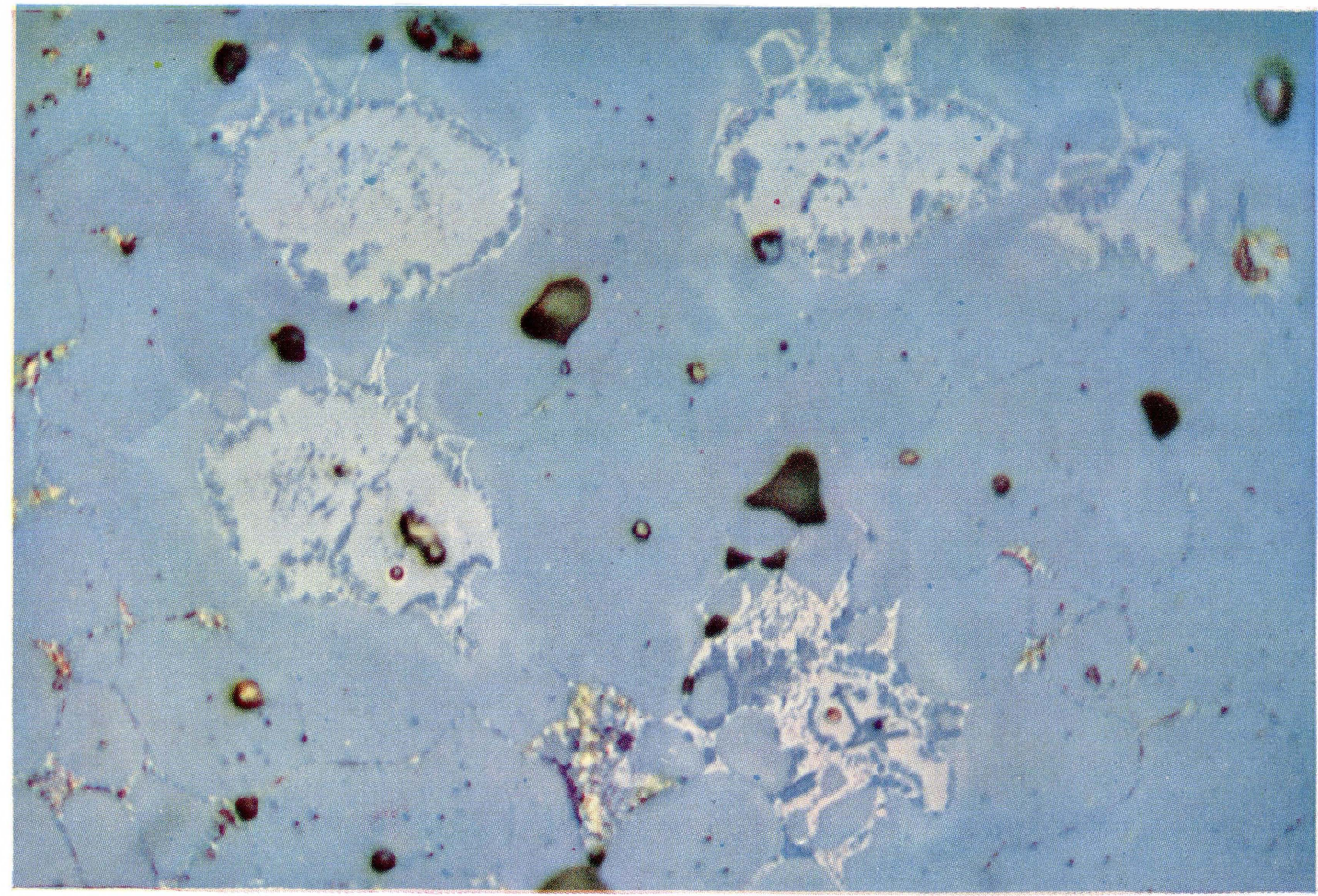

FIgURE 5. Eutectic type structure developed between some free niobium and $\mathrm{Nb}_{4} \mathrm{Sn}$ after reheating a specimen of nominal $80 \% \mathrm{Nb}-20 \% \mathrm{Sn}$ composition quenched from 800 , to about $1,850{ }^{\circ} \mathrm{C}$.

The matrix is $\mathrm{Nb}_{4} \mathrm{Sn}$. X1000.

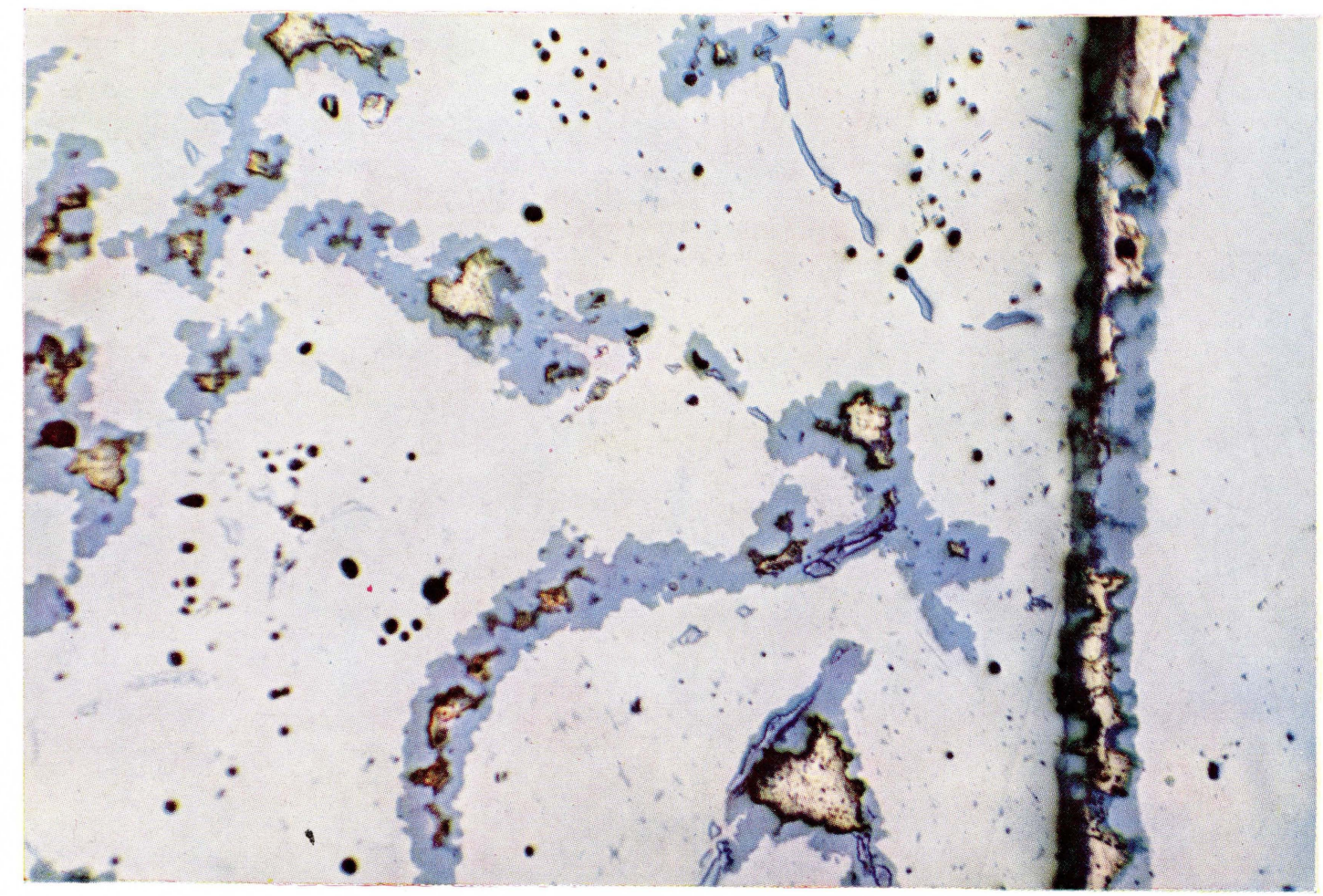

FIGURE 6. Joint developed between the porous niobium bar (left) and the electron beam melted niobium rod (right).

$\mathrm{X} 100$. 


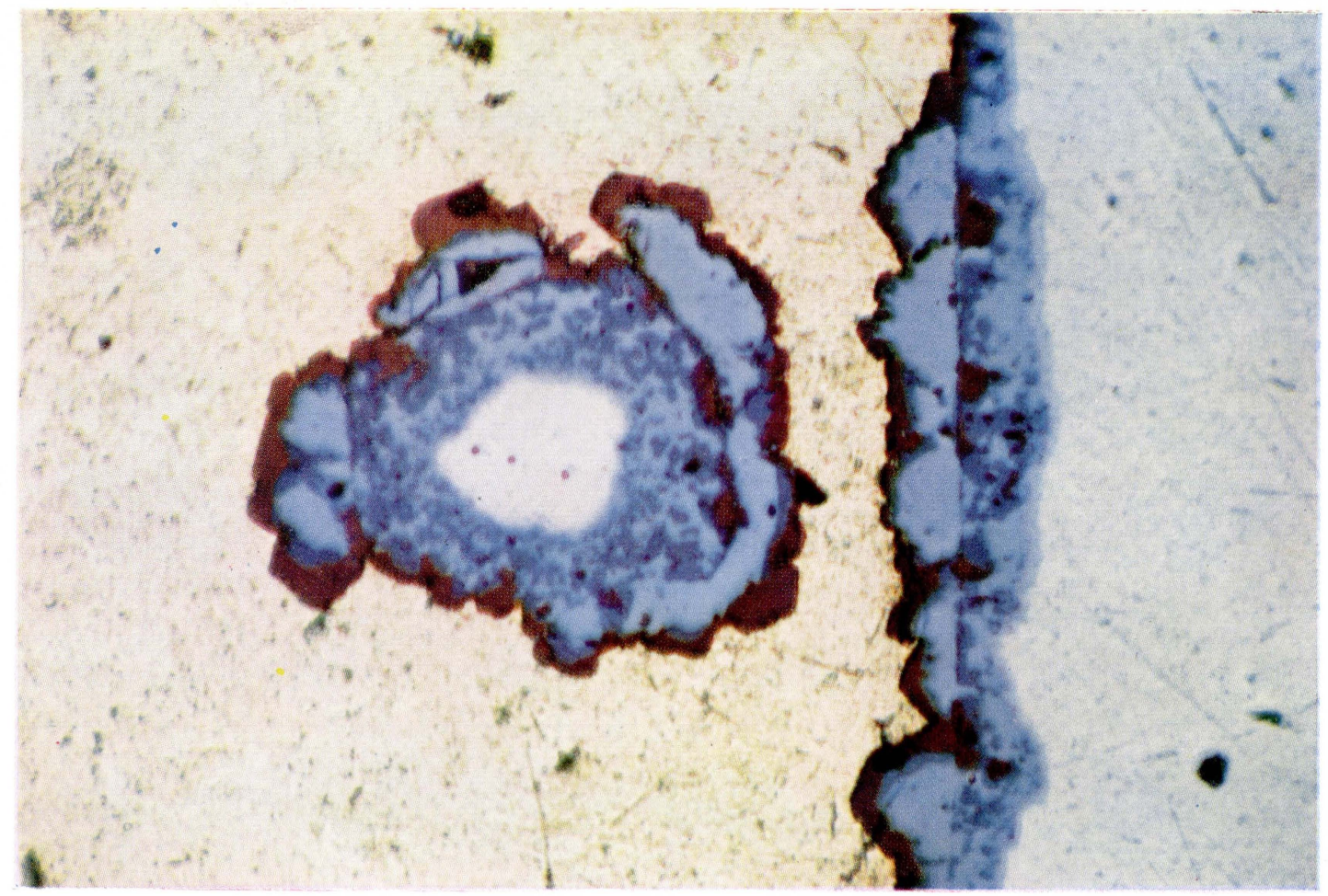

Figure 7. Cross section of a nominal 0.004-in. niobium wire heated for $8 \mathrm{hr}$ at $1,000{ }^{\circ} \mathrm{C}$ in a bath of molten tin and furnace cooled.

The niobium shell is at the right. X500.

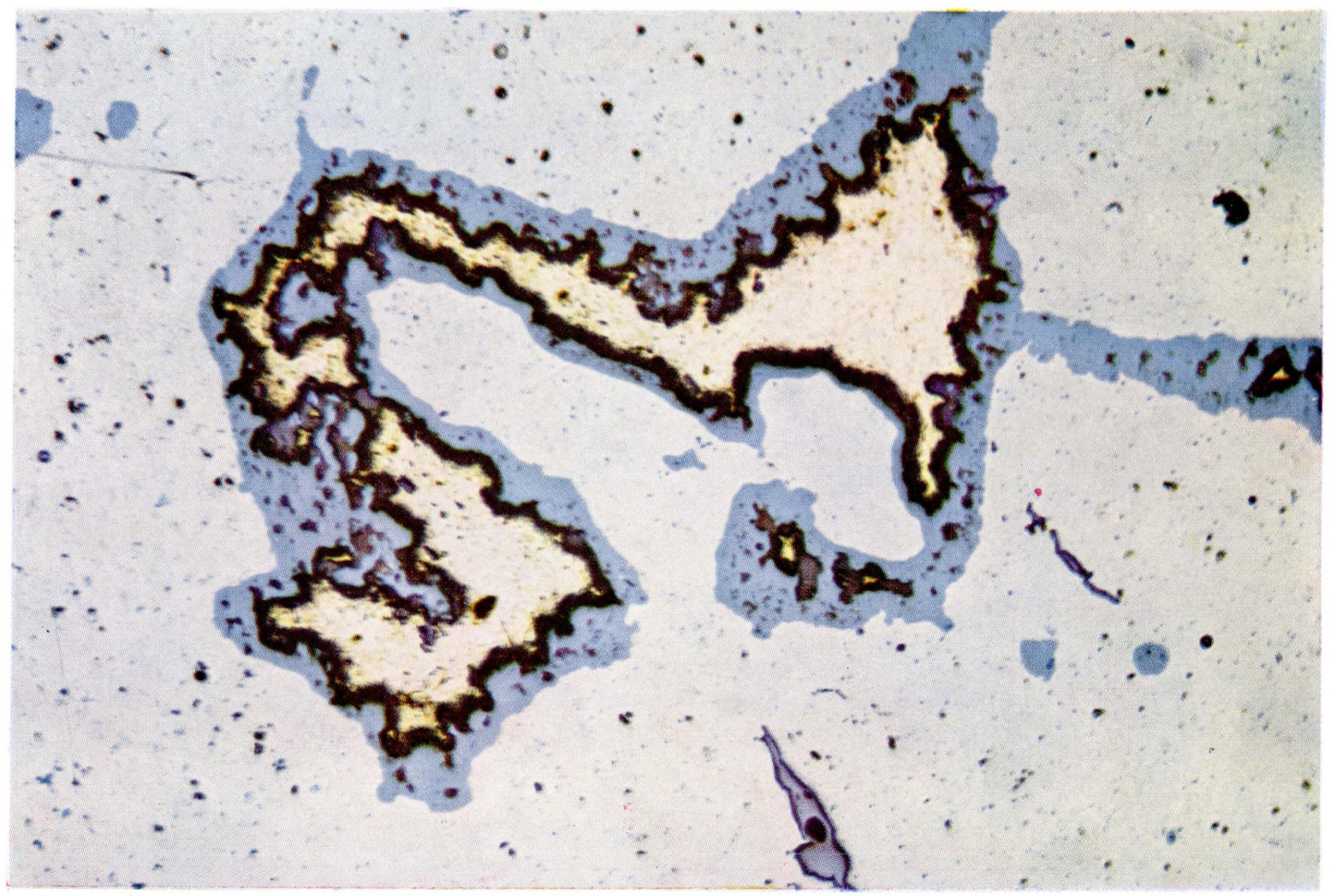

FIGURE 8. Interior of porous niobium bar after diffusion in a bath of molten tin for 16 hr at $1,000{ }^{\circ} \mathrm{C}$ followed by furnace cooling. 


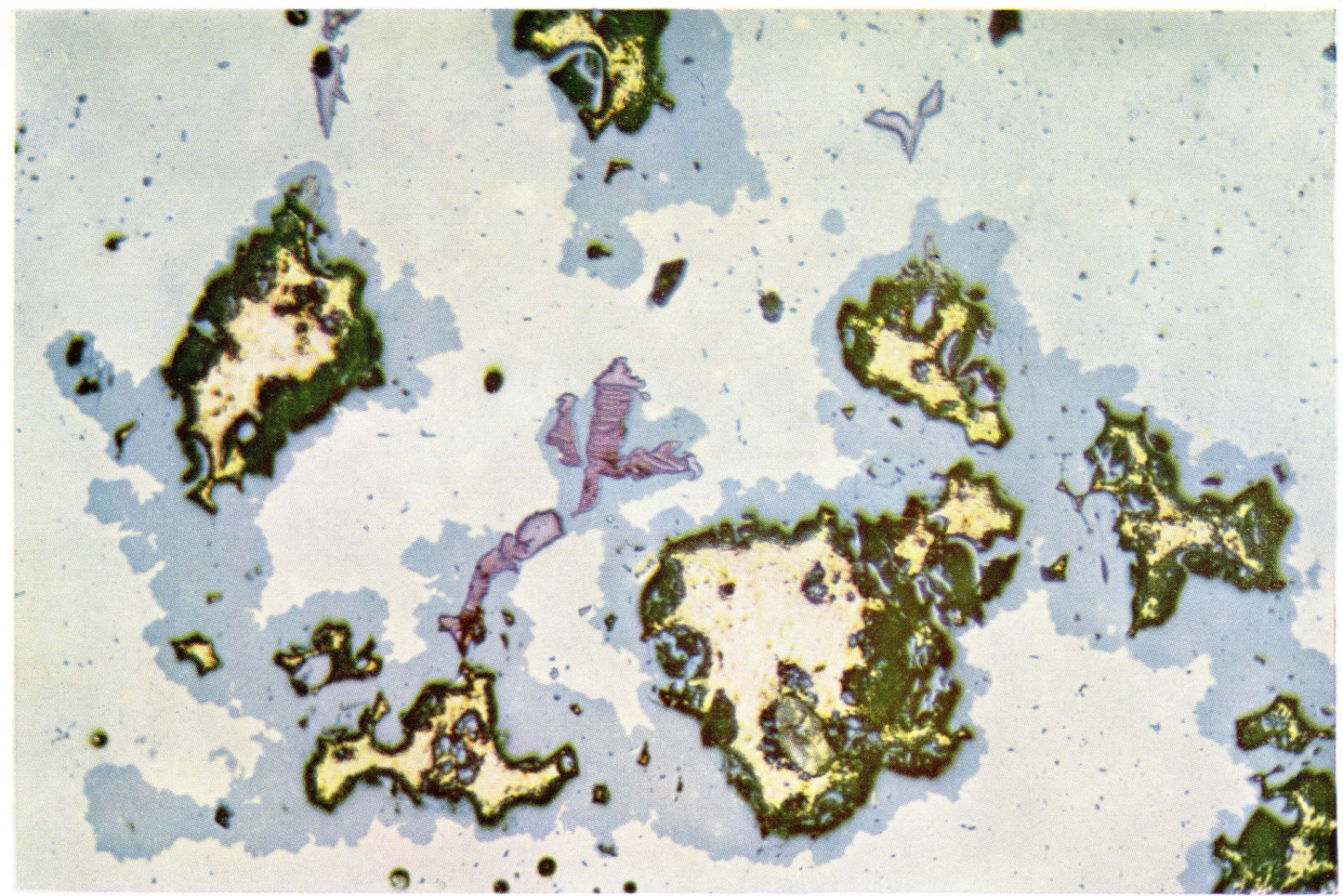

FIGURE 9. Interior of porous niobium bar after diffusion in a bath of molten tin for $32 \mathrm{hr}$ at $1,200{ }^{\circ} \mathrm{C}$ followed by water quench.

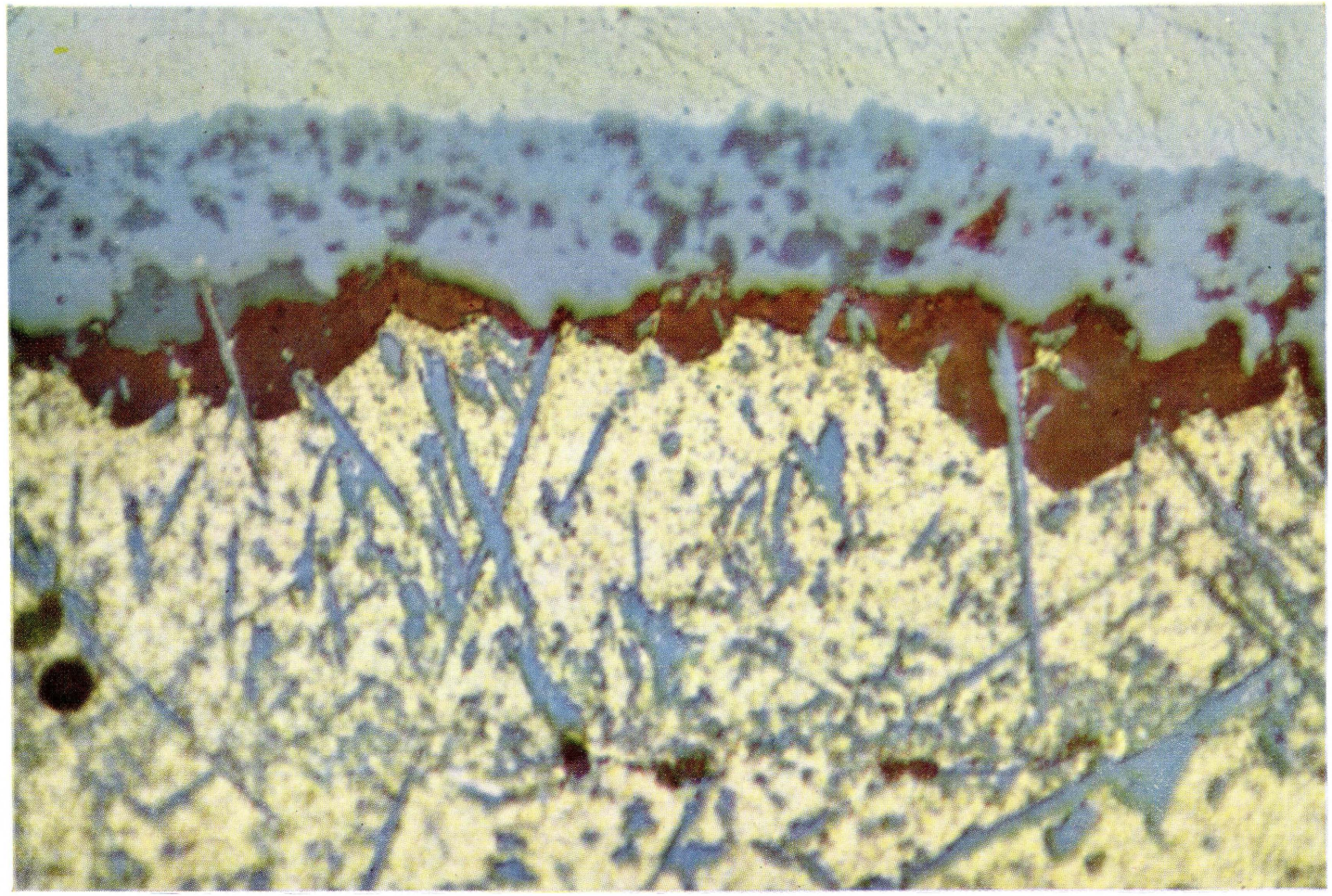

Figure 10. Exterior of niobium shell after diffusion in a bath of molten tin for $8 \mathrm{hr}$ at $1,000{ }^{\circ} \mathrm{C}$ followed by furnace cooling.

The needles are $\mathrm{Nb}_{4} \mathrm{Sn}$. X1000. 


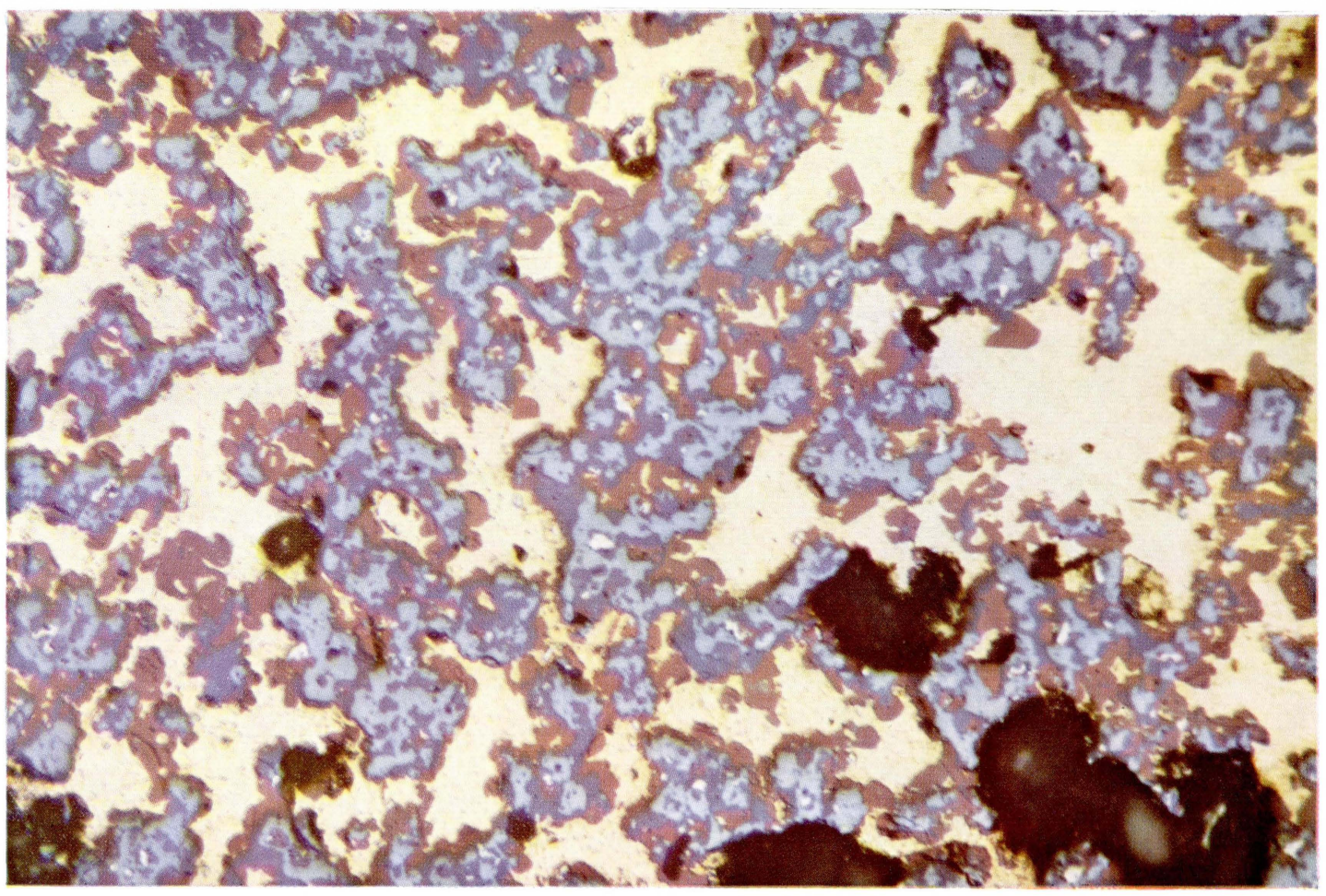

FIGURE 11. Interior of thermal analysis specimen (nominal $\mathrm{Nb}_{2} \mathrm{Sn}_{3}$ hot pressed pellet) after heating to $1050{ }^{\circ} \mathrm{C}$ at $3{ }^{\circ} \mathrm{C} / \mathrm{min}$ followed by cooling to room temperature also at $3^{\circ} \mathrm{C} / \mathrm{min}$.

$\mathrm{X} 200$.

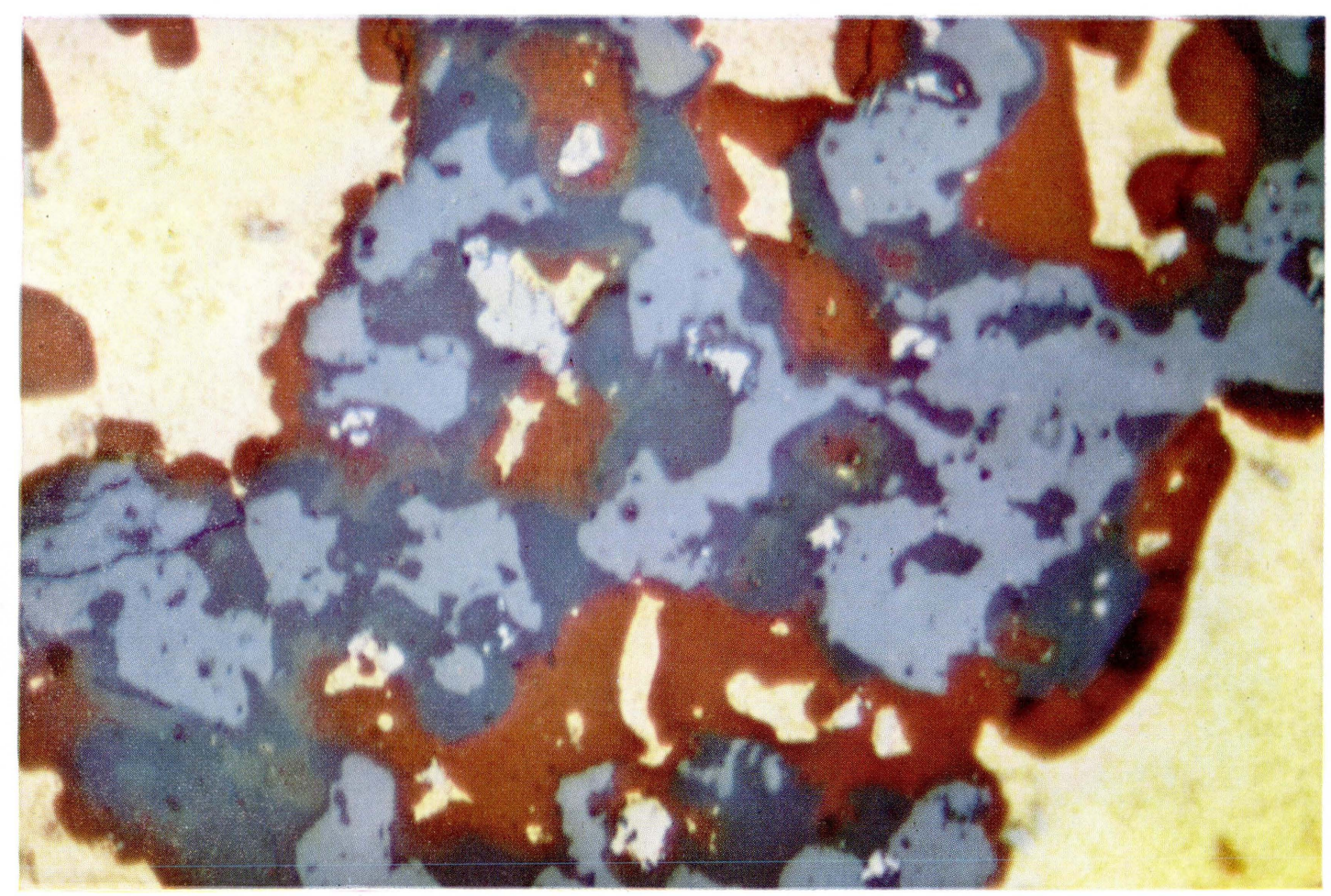

FIGURE 12. Interior of thermal analysis specimen (nominal $\mathrm{Nb}_{2} \mathrm{Sn}_{3}$ hot pressed pellet) after heating to $1,050{ }^{\circ} \mathrm{C}$ at $3{ }^{\circ} \mathrm{C} / \mathrm{min}$ followed by cooling to room temperature also at $3{ }^{\circ} \mathrm{C} / \mathrm{min}$.

$\mathrm{X} 1000$.

(Paper 66A4-171) 


\section{Publications of the National Bureau of Standards*}

\section{Selected Abstracts}

The interaction between an obliquely incident plane electromagnetic wave and an electron beam in the presence of a static magnetic field of arbitrary strength, K. H. B. Wilhelmsson, J. Research NBS 66D (Radio Prop.) No. 4, (JulyAugust 1962).

The purpose of the paper is to study theoretically the interaction between an obliquely incident plane electromagnetic wave and an electron beam. We assume that a static magnetic field of arbitrary strength is present in the axial direction. Machine computations made for the case of a cylindrical electron plasma show that resonances occur in the backscattering cross section as a function of the angle of incidence of the plane wave. The dependence of the resonance angles on the plasma frequency for fixed gyrofrequency suggests a possibility to utilize the results of the investigation for diagnostics of a cylindrical plasma.

Magnetotelluric fields in the frequency range 0.03 to 7 cycles per kilosecond: Part I. Power spectra, C. W. Horton and A. A. J. Hoffman, J. Research NBS 66D (Radio Prop.) No. 4 (July-A ugust 1962).

Power spectra of the horizontal components of the magnetic field and the telluric field are computed for data recorded on 1 and 2 September 1957 at the Soviet Magnetic Observatory in Tbilisi. Power spectra of the East-West telluric field component are computed for 20 September 1957 for Soviet stations located at Lvov, Tbilisi, and Ashkhabad. All analyses are based on microfilm copies furnished by the IGY World Data Center A. Each power spectrum shows a frequency dependence over a frequency range of 0.03 to $7 \mathrm{c} / \mathrm{ks}$ of the form $P_{0} f^{-n}$ where $n$ varies from 1.1 to 2.5 . The coherency between orthogonal components of the telluric and magnetic fields is computed for the data from Tbilisi. Magnetotelluric power spectra from USSR, Canada, Texas, and Massachusetts are plotted on a common graph to show the frequency dependence over the range 0.03 to $400 \mathrm{c} / \mathrm{ks}$.

Magnetotelluric fields in the frequency range 0.03 to 7 cycles per kilosecond: Part II. Geophysical interpretation, C. W. Horton and A. A. J. Hoffman, $J$. Research NBS 66D (Radio Prop.) No. 4 (July-August 1962).

The power spectra computed in Part I for Tbilisi, USSR are used to compute apparent resistivity in accordance with a formula developed by Cagniard. It is found that both components of the telluric field yield a value of 6 ohmmeters for the apparent electrical resistivity of the earth. The data do not extend over a sufficiently wide range of frequency to permit conclusions about the stratification. There is no evidence of horizontal anisotropy of the earth's resistivity.

The magnetic power spectrum for the earth's ambient field is corrected for the tranmission losses in the ionosphere to yield the power spectrum of the magnetic field incident on the earth. The major part of the variation with frequency is eliminated by this correction.

Standard X-ray diffraction powder patterns, H. E. Swanson, M. C. Morris, R. P. Stinchfield, and E. H. Evans, NBS Mono. 25-Section 1 (March 9, 1962) 40 cents.

Forty-six standard X-ray diffraction powder patterns are presented. Fourteen are to replace twelve patterns already given in the X-ray Powder Data File, and thirty-four are for substances not previously included. The X-ray Powder Data File is a compilation of diffraction patterns from many sources and is used for the identification of unknown crystalline materials by matching spacing and intensity measurements. The patterns were made with a Geiger counter X-ray diffractometer, using samples of high purity. The $d$-values were assigned Miller indices determined by comparison with calculated interplanar spacings and from space group considerations. The densities and lattice constants were calculated, and the refractive indices were measured whenever possible.
Included are X-ray data for the following forty-six substances: $\left(\mathrm{NH}_{4}\right)_{2} \mathrm{OsCl}_{6}, \mathrm{Al}_{2} \mathrm{SiO}_{4}(\mathrm{~F}, \mathrm{OH})_{2}$, topaz, $\mathrm{BiF}_{3}, \mathrm{CeCl}_{3}, \mathrm{CeVO}_{4}$, $\mathrm{CsClO}_{4}, \mathrm{CsV}\left(\mathrm{SO}_{4}\right)_{2} \cdot 12 \mathrm{H}_{2} \mathrm{O}, \mathrm{Er}_{3} \mathrm{Ga}_{2}\left(\mathrm{GaO}_{4}\right)_{3}, \mathrm{EuCl}_{3}, \mathrm{EuOCl}$, $\left.\mathrm{GdF}_{3}, \mathrm{GdOCl}, \mathrm{Gd}_{2} \mathrm{O}_{3}, \mathrm{Ho}\left[\mathrm{C}_{2} \mathrm{H}_{5}\right) \mathrm{SO}_{4}\right]_{3} \cdot 9 \mathrm{H}_{2} \mathrm{O}, \mathrm{FeAs}, \mathrm{LaBO}_{3}$, $\mathrm{LaCl}_{3}, \quad \mathrm{La}_{2} \mathrm{Mg}_{3}\left(\mathrm{NO}_{3}\right)_{12} \cdot 24 \mathrm{H}_{2} \mathrm{O}, \mathrm{Li}_{2} \mathrm{MoO}_{4}, \mathrm{Li}_{2} \mathrm{O}, \mathrm{Li}_{2} \mathrm{WO}_{4}$, $\mathrm{Lu}_{2} \mathrm{O}_{3}, \quad \mathrm{Mg}_{2} \mathrm{Al}_{4} \mathrm{Si}_{5} \mathrm{O}_{18}$ (low-cordierite), $\mathrm{Mg}_{2} \mathrm{Al}_{4} \mathrm{Si}_{5} \mathrm{O}_{18}$ (highcordierite), $3 \mathrm{Mg}_{2} \mathrm{SiO}_{4} \cdot \mathrm{MgF}_{2}$ (humite), $\mathrm{NdBO}_{3}, \quad \mathrm{NdCl}_{3}$, $\mathrm{Nd}_{3} \mathrm{GA}_{2}\left(\mathrm{GaO}_{4}\right)_{3}$, NiAsS (gersdorffite), $\mathrm{NiCO}_{3}, \mathrm{NiS}$, millerite, $\mathrm{KH}_{2} \mathrm{AsO}_{4}, \quad \mathrm{PrCl}_{3}, \quad \mathrm{SmCl}_{3}, \quad \mathrm{SmF}_{3}, \quad \mathrm{Sm}_{3} \mathrm{Ga}_{2}\left(\mathrm{GaO}_{4}\right)_{3}, \quad \mathrm{SmOCl}$, $\mathrm{Ag}_{2} \mathrm{CO}_{3}, \mathrm{Ag}_{2} \mathrm{O}, \mathrm{Na}_{2} \mathrm{MoO}_{4}, \mathrm{Na}_{2} \mathrm{WO}_{4}, \mathrm{Tl}_{2} \mathrm{WO}_{4}, \mathrm{Yb}_{3} \mathrm{Ga}_{2}\left(\mathrm{GaO}_{4}\right)_{3}$, $\mathrm{Y}_{3} \mathrm{Ga}_{2}\left(\mathrm{GaO}_{4}\right)_{3}, \mathrm{YOCl}, \mathrm{Zr}\left(\mathrm{IO}_{3}\right)_{4}$.

Theory and methods of optical pyrometry, H. J. Kostkowski and R. D. Lee, NBS Mono. 41 (March 1, 1962) 25 cents. A detailed review of the theoretical methods of optical pyrometry and the application of these methods at the National Bureau of Standards in realizing, maintaining, and distributing the International Practical Temperature Scale above $1063{ }^{\circ} \mathrm{C}$ is presented. In the theoretical presentation, the concepts of effective and mean effective wavelengths are introduced, and various equations relating these parameters to each other and other physical quantities are derived. The important features of precision visual optical pyrometers are discussed and a number of blackbody sources and tungstrip lamps described. Detailed experimental procedures and results of primary and secondary calibrations of optical pyrometers at NBS are given. Finally, recommendations for achieving high precision and accuracy and the fundamental limitations in visual optical pyrometry are presented.

Standard materials issued by the National Bureau of Standards. A descriptive list with prices, NBS Misc. Publ. 241 (March 12, 1962) Supersedes C 552, 3d edition, 30 cents.

A descriptive listing of the various Standard Materials issued by the National Bureau of Standards is given. A schedule of fees and weights, as well as directions for ordering, is included. Summarized tables of analyses are presented, to indicate the type of standards of composition presently available. Announcements of new standards will be made in the Federal Register, in scientific and trade journals, and in the Standard Materials column of the National Bureau of Standards Technical News Bulletin. The current status of the various standards will be indicated by an insert sheet available from the Bureau.

\section{A tabulation of the thermodynamic properties of normal hydro-} gen from low temperatures to $300{ }^{\circ} \mathrm{K}$ and from 1 to 100 atmospheres, J. W. Dean, NBS Tech. Note 120 (Pb161621) (1961) \$1.75.

Pressure, volume, temperature, internal energy, enthalpy, and entropy of normal hydrogen gas have been tabulated along isobars in $1^{\circ} \mathrm{K}$ temperature steps. The range covered is from the saturation temperature to $300{ }^{\circ} \mathrm{K}$ and from a pressure of 1 to 100 atmospheres. The source of data is the Research Paper 1932 of the National Bureau of Standards Journal of Research. The method is described by which the data presented in Research Paper 1932 is reduced to properties directly useful for engineering calculations. A method is also described for estimating the effect of ortho-para compositions upon the tabulated properties.

Tabular values are presented in the dimensional units of the metric system. The tabulations are also available in the dimensional units of the British system as Technical Note No. 120, Supplement A.

A survey of the literature on heat transfer form solid surfaces to cryogenic fluids, R. J. Richards, W. G. Steward, and R. B. Jacobs, NBS Tech. Note 122 (PB 161623) (1961) \$1.25.

A bibliography of 156 references on heat transfer from solid surfaces to fluids and related phenomena is presented. Heat transfer data obtained from experimental work on cryogenic fluids are presented in graphical form. The theoretical and 
empirical formulations appearing in the references are presented. In those cases where sufficient information is available to make numerical computations, the formulations are presented graphically to permit comparison with the results of the experimental work.

Functional and design problems of the NBS RF voltage bridge, L. F. Behrent, NBS Tech. Note 123 (PB161624) (1961) \$1.00. A detailed presentation is given of the practical solutions to the design and operating problems encountered in constructing a Thermistor Bridge similar to that used by the NBS for RF Voltage Standaridization. Measurement and operating techniques, critical structural features, as well as the proper use of available components are discussed.

Provisional thermodynamic functions for para-hydrogen, $H$. M. Roder and R. D. Goodwin, NBS Tech. Note 130 (PB161631) (1961) \$3.00.

New PVT data recently obtained at this laboratory were used to compute tabular values of internal energy, enthalpy, and entropy of para-hydrogen. These properties, together with specific volume, are presented here as functions of temperature and pressure. The new data encompassed the temperature range $20^{\circ}$ to $100{ }^{\circ} \mathrm{K}$ at pressures up to $340 \mathrm{~atm}$. Earlier data were used to extend the tables to $300^{\circ} \mathrm{K}$. Above $100{ }^{\circ} \mathrm{K}$ the upper limit of pressure is $100 \mathrm{~atm}$. The information is also presented in the form of thermodynamic charts. In supplement A to this report the thermodynamic tables and charts are presented in units of: psia, degrees Rankine, BTU pounds, and cubic feet.

Photoionization of atoms and molecules, F. L. Mohler, NBS Tech. Note 131 (PB161632) (1962) \$1.25.

This is a review of experimental results on photoionization of atoms and some molecules. There are some quantitative data on all the alkalies, magnesium, calcium, and thallium and all rare gases except xenon. Results are given for the common gases; hydrogen, nitrogen, oxygen, $\mathrm{CO}, \mathrm{CO}_{2}, \mathrm{NO}$, $\mathrm{K}_{2} \mathrm{O}, \mathrm{NO}_{2}, \mathrm{H}_{2} \mathrm{O}$, and $\mathrm{CH}_{4}$. Autoionization, excitation to a state above the ionization threshold followed by transition to the ionized state, can be an important factor. Often the broad autoionization lines mask the true continuum. There are some mass spectrometric measurements of photoionization products for most of these molecules.

Low temperature thermometry, R. P. Hudson, Experimental Cryophys. p. 214-25.3 (1961).

A discussion is given of apparatus and methods for thermometry in the range $1^{\circ}-100^{\circ} \mathrm{K}$ in a style and brevity suited to an entry in a scientific encyclopaedia.

Photolysis of acetone- $d_{6}$ in the presence of propane-2, 2-d 2 . Decomposition of the $n$-propyl radical, W. M. Jackson and J. R. MeNesby, J.Am. Chem. Soc, 83, 4891-4896 (1961).

Methyl- $d_{3}$ radicals generated by photolysis of acetone- $d_{6}$ react with acetone- $d_{6}$ and propane-2, $2-d_{2}$ producing methane by the following reactions

(1) $\mathrm{CD}_{3}+\mathrm{CD}_{3} \mathrm{COCD}_{3} \rightarrow \mathrm{CD}_{4}+\mathrm{CD}_{2} \mathrm{COCD}_{3}$

(2) $\mathrm{CD}_{3}+\mathrm{CH}_{3} \mathrm{CD}_{2} \mathrm{CH}_{3} \rightarrow \mathrm{CD}_{4}+\mathrm{CH}_{3} \mathrm{CDCH}_{3}$

(3) $\mathrm{CD}_{3}+\mathrm{CH}_{3} \mathrm{CD}_{2} \mathrm{CH}_{3} \rightarrow \mathrm{CH}_{3} \mathrm{H}+\mathrm{CH}_{2} \mathrm{CD}_{2} \mathrm{CH}_{3}$

Ratios of rate constants obtained are approximately temperature independent and

$$
k_{1} / k_{3}=1.10
$$$$
k_{2} / k_{3}=0.58
$$

Analogous ratios for $\mathrm{CH}_{3}$ radicals are indistinguishable from those for the $\mathrm{CD}_{3}$ species. Decomposition of $n$-propyl to $\mathrm{H}$ and propylene is found to proceed at a much lower rate than suggested by Kerr and Trotman-Dickenson.

Consideration of kinetic and thermochemical evidence suggests the best value for the rate constants $k_{5 a}$ and $k_{4 a}$ are:

(5a) $\mathrm{CH}_{3} \mathrm{CH}_{2} \mathrm{CH}_{2} \rightarrow \mathrm{H}+\mathrm{CH}_{3} \mathrm{CH}=\mathrm{CH}_{2}$

(4a) $\mathrm{CH}_{3} \mathrm{CH}_{2} \mathrm{CH}_{2} \rightarrow \mathrm{CH}_{3}+\mathrm{CH}_{2}=\mathrm{CH}_{2}$

$$
k_{5 a}=10^{14.1} \exp (-37,000 / R T) \quad \sec ^{-1}, \quad k_{4 a}=10^{13.9} \exp
$$

$$
(-31,000 / R T) \mathrm{sec}^{-1}
$$

Analysis of the absorption spectrum of $\mathrm{YbCl}_{3} \cdot 6 \mathrm{H}_{2} \mathrm{O}$, J. C. Eisenstein, J. Chem. Phys. 35, No. 6, 2097-2100 (Dec. 1961). The measurements of Dieke and Crosswhite on the absorption spectrum of $\mathrm{YbCl}_{3} \cdot 6 \mathrm{H}_{2} \mathrm{O}$ are discussed. Their interpretation of the spectrum is extended by the identification of two of the weaker lines. The entire spectrum is considered on the basis of crystal field theory, and the possibility of determining the parameters of the crystal field potential is assessed. It is concluded that the terms in the potential with axial symmetry are small, and that additional small terms with twofold symmetry are present. The spin-orbit coupling constant is determined to be $-2924 \mathrm{~cm}^{-1}$.

A lattice with an unusual frequency spectrum, R. J. Rubin and R. Zwanzig, J. Math. Phys. 2, No. 6, 861-864 (Nov.Dec. 1961).

The lattice is a special rooted Cayley tree, generated by $N$ successive $m$ fold branchings. With each point of the tree are associated a mass $M$ and a position coordinate $\chi_{i}$. All end points are held fixed at $\chi_{i}=0$. The potential energy is $V=\frac{1}{2} \Sigma_{i, j}, K_{i j}\left(\chi_{i}-\chi_{i}\right)^{2}$, where $K_{i j}=K$ if $i$ and $j$ are connected neighbors and neither is an end point, $K_{i j}=\alpha K$ if $i$ and $j$ are connected neighbors and either is a branch tip point, and $K_{i j}=0$ if $i$ and $j$ are not connected neighbors. The allowed frequencies of vibration are obtained for two different cases: In the first case all springs are identical $(\alpha=1)$, and in the second case the springs connecting interior points to the branch tips are cut $(\alpha=0)$. In the case in which all force constants are the same, the allowed frequencies of vibration, in the limit of infinite $N$, are given by $\omega(r)=(K / M)^{\frac{1}{2}}[m+1$ $\left.-2 m^{\frac{1}{2}} \cos r \pi\right]^{\frac{1}{2}}$, where $r$ is any rational number between zero and one. The fraction of all normal modes having precisely the value $\omega(r)$ is $\rho[\omega(r)]=(m-1)^{2} /\left(m^{\alpha}-1\right)$, where $r$ is expressed as the ratio $r=p / q$ of relatively prime integers $p$ and $q$. The frequency spectrum is dense within the interval $\left(m^{\frac{1}{2}}-1, m^{\frac{1}{2}}+1\right)$; and $\rho[\omega]$ is discontinuous at every $\omega$ for which it does not vanish.

Net heat of combustion and other properties of kerosine and related fuels, G. T. Armstrong, L. Fano, R. S. Jessup, S. Marantz, T. W. Mears, and J. A. Walker, J. Chem. Eng. Data \%, No. 1, 10\%-116 (Jan. 1962).

Data are reported on the net heat of combustion $\left(Q_{p}[\right.$ net $\left.]\right)$, API Gravity $(G)$, aniline point $(A)$, hydrogen, carbon, and sulfur content, composition in terms of hydrocarbon types, and density of 139 fuels. These fuels are mainly petroleumdistillate kerosines of varying degrees of refinement or alkylates boiling in the kerosine range and represent the production of a large number of refineries. The remaining fuels are special formulations developed for the Wright Air Development Center.

Equations have been derived to represent $Q_{p}$ (net) as a function of $(A \times G)$, and of hydrocarbon-type composition for the 110 petroleum-distillate kerosines. The net heat of combustion can be represented by a linear function of $(A \times G)$ with a standard deviation of $22 \mathrm{Btu} / \mathrm{lb}(0.12 \%)$ and a maximum deviation of $+80 \mathrm{Btu} / \mathrm{lb}(0.43 \%)$ for a large range of values of $(A \times G)$. The equations relating $Q_{p}$ (net) to the hydrocarbon-type composition give a larger standard deviation than the $(A \times G)$ equation when applied to the same 110 fuels. The results calculated from any of these equations for fuels classes other than that used in their derivation are not satisfactory.

On the thermodynamic properties of fluids, E. H. Brown, Inst. Intern. Du Froid, Intern. Inst. of Refrigeration, Commission 1, 169-178 (1960).

Methods for determining the general behaviour of the thermodynamic properties of fluids over the entire pressure-temperature domain, including models of ideal fluids and condensing fluids and descriptions of the most important "characteristic curves" (curves on which the compressibility factor or its derivatives become zero), are outlined. Some of the results are applied to specific problems, such as furnishing some means of judging between conflicting sets of data on the shape and location of the Joule-Thomson inversion curve of hydrogen.

Double probe measurements of ionization in active nitrogen, H. P. Broida and I. Tanaka, J. Chem. Phys. 36, No. 1, 236-238 (Jan. 1962).

Electron temperatures and ion densities have been measured in nitrogen afterglows in a flow system at short times after the discharge. In pure nitrogen a maximum occurs in the 
ionization density and in the electron temperature at 5 to 10 msec after the discharge. The position of this maximum coincides with the visible short-duration nitrogen afterglow in which $\mathrm{N}_{2}^{+}$emission is prominent. Small amounts of added impurity decrease this ion density but cause an increase in the ion density at longer times, reaching a second maximum at 80 to 100 msec after the discharge. These results show that ions and electrons are being produced continuously in nitrogen afterglows and that the rate of production is affected strongly by impurities.

Intramolecular rearrangements. III. Formation of 1-methylcyclobutanol in the photolysis of 2-pentanone, P. Ausloos and R. E. Rebbert, J. Am. Chem. Soc. 83, $4897-4899$ (1961).

1-Methyl cyclobutanol has been isolated as a product in the vapor-phase photolysis of 2-pentanone. The yield of the alcohol diminishes with decrease in pressure and wavelength. Oxygen and nitric oxide reduce the yields of acetone, ethylene, and 1-methyl cyclobutanol. In the photo-chemical decomposition of the liquid phase, the ratio: acetone/1-methyl cyclobutanol is independent of wavelength and only slightly dependent on temperature.

Re-examination of the polymorphism of dicalcium silicate, D.K. Smith, A. J. Majumdar, and F. Ordway, J. Am. Ceram. Soc. 44, No. 8, 405-411 (Aug. 1961)

Samples of $\mathrm{Ca}_{2} \mathrm{SiO}_{4}$ have been prepared by three different methods. These samples were examined by differential thermal analysis, high-temperature X-ray diffraction, and air quenching of pellets. It was found that the $\beta$ modification, on cooling, converts completely and rapidly to the $\gamma$ modification and dusts only if it has been heated above $1420^{\circ} \pm 10^{\circ} \mathrm{C}$. If the sample was not heated above this critical temperature, a mixture of the $\beta$ and $\gamma$ forms always resulted at room temperature.

The addition of 0.5 percent of $\mathrm{CaO}, \mathrm{SiO}_{2}, \mathrm{Al}_{2} \mathrm{O}_{3}, \mathrm{Fe}_{2} \mathrm{O}_{3}$, or $\mathrm{MgO}$ showed no effect on the sequence of phases for samples cooled from above the critical temperature. However, when these same samples were cooled from below $1410^{\circ} \mathrm{C}$, the final room temperature product was not the same for all samples. On the other hand, the additional 0.5 percent of $\mathrm{Na}_{2} \mathrm{O}, \mathrm{K}_{2} \mathrm{O}, \mathrm{Cr}_{3} \mathrm{O}_{2}$, and $\mathrm{B}_{2} \mathrm{O}_{3}$ prevented the formation of the $\gamma$ modification regardless of the temperature from which the sample was cooled.

The critical temperature correlates with the transformation temperature for the $\alpha-\alpha^{\prime}$ inversion. A theory relating this inversion to the completeness of $\beta \rightarrow \gamma$ transformation is presented.

Fluorine flame calorimetry, G. T. Armstrong, Books, Experimental Thermochemistry II, Ch. 7, 129-145 (Interscience Publ., London, England, 1962).

The necessity for flame calorimetry with elemental fluorine for determining heats of formation of fluorocarbons, hydrofluorocarbons and other fluorine compounds is justified on the grounds that elemental fluorine must be used in some reactions under any circumstance, that less ambiguity in the heat measurement is encountered if no additional elements are introduced into reactions of the compounds of interest, and that it is also desirable to check the results obtained by other calorimetric methods. A flame calorimeter has been developed at the National Bureau of Standards and used for measurements of heats of reaction of ammonia and methane with fluorine. The amounts of reaction determined by weighing the methane introduced and hydrogen fluoride formed have a mean difference of 0.13 per cent. Enthalpy correction for hydrogen fluoride imperfections are tabulated over the pressure range 0.1 to 0.5 atm at $26^{\circ}, 32^{\circ}, 38^{\circ}, 44^{\circ}$, and $56^{\circ}$. The accuracy of measurements of heat of reaction is about 0.3 per cent (standard deviation of the mean). Revisions of the heats of formation of $\mathrm{HF}$ and $\mathrm{CF}_{4}$ are suggested.

Polymorphism in monobromoacetic acid and the diagram of state of dichloroacetic acid at elevated pressures, A. R. Glasgow and J. Timmermans, Bull. Soc. Chim. Belges $\mathbf{7 0 .}$ 623-641 (1961).

Piezometric measurements to 5000 atmospheres have shown that dichloroacetic acid occurs in only one crvstalline form monobromoacetic acid exists in three forms with triple points at about $50.5^{\circ} \mathrm{C}$ and $120 \mathrm{~kg} / \mathrm{cm}^{2}$ (liq, C I, C II) and $53^{\circ} \mathrm{C}$ and $260 \mathrm{~kg} / \mathrm{cm}_{2}$ (liq, C JI, C III). The transitions C I to CII and CII to C III have negative temperature-pressure coefficients $(d T / d P)$ and occur only at elevated pressures. No example has been previously reported of an organic compound which has two successive solid transitions with negative $d T / d P$ coefficients such as were observed for monobromoacetic acid.

Values of $d T / d P, \Delta H$, and $\Delta S$, calculated from the piezometric data, are given for the fusion of dichloroacetic acid and for the two solid transitions and the fusion (C III. liq) of monobromoacetic acid. An evaluation of purity of the acids from time-pressure data is discussed.

Superconducting magnets, R. H. Kropschot and V. Arp, Cryogenics 2, No. 1, 1-15 (Sept. 1961).

The abrupt and total disappearance of electrical resistivity of certain metals at liquid helium temperatures is known as superconductivity. The use of superconductors for electromagnet windings eliminates the totally wasted Joule heating of conventional electromagnets and hence results in important power savings. However, electrical resistance is restored by magnetic fields greater than a certain critical value which depends upon the physical properties of the particular superconductor.

Certain alloys appear to have critical fields of 100 kgauss or greater, and theory indicates that very thin films of some of the more common metals may have critical fileds of about this same magnitude. Small size superconducting magnets producing up to 15 kgauss have been made. Large size magnets using the high field superconductors to produce fields up to 100 kgauss appear feasible with present technology.

The operating cost of a large, 100 kgauss superconducting magnet and its associated refrigeration system is $10^{2}$ to $10^{4}$ times less than the conventional magnet it replaces; it is expected that this will have an important effect on nuclear physics and plasma physics research.

An introduction to flame photometry and a review of recent studies, M. Margoshes, Book, Physical Techniques in Biological Research, W. L. Mastok, Ed., IV, 215-260 (Academic Press, New York, N.Y., 1962).

Accurate and precise analysis with the flame photometer requires knowledge of the basic principles of instrumentation, excitation in the flame, preparation of standards and samples, and possible sources of error. This chapter is intended to provide such information, primarily to biologists and biochemists.

A brief historical introduction is followed by discussion of the chemical and physical processes involved in the introduction of the sample into the flame and the subsequent excitation of atomic and molecular spectra. The other components of the flame photometer, the monochromator and the detecting and measuring systems, are then considered. A summary of areas of application of flame photometry is followed by an extensive discussion of major causes of error in flame photometric analysis, including possible errors in the preparation of samples and standards, and those arising in the vaporization and excitation steps and in the components of the instrument. Some means of recognizing and circumventing these sources of error are mentioned.

The chapter concludes with a discussion of some recent developments in flame photometry, including the use of hightemperature flames as sources, the application of organic solvents (particularly in connection with liquid-liquid extraction), and atomic absorption spectroscopy.

The ionization constant of $a$-nitrophenol from 0 to $60^{\circ}, \mathrm{G}$. F. Allen, R. A. Robinson, and V. E. Bower, J. Phys. 'Chem. 66, No. 1, 171-172 (1962).

The spectrophotometric method has been used to measure the dissociation constant of $p$-nitrophenol in aqueous solution from 0 to $60^{\circ} \mathrm{C}$. The dissociation constant, $K_{a}$, is $7.03 \times 10^{-8}$ at $25^{\circ} \mathrm{C}$. It is given as a function of the absolute temperature (T) by

$$
-\log K_{a}=\frac{2186.53}{T}-4.0475-0.01298 T .
$$


The thermodynamic quantity, $\Delta H^{\circ}$, is computed as 4.725 cal. mole ${ }^{-1}$ at $25{ }^{\circ} \mathrm{C}$ and compared with 4,700 cal. mole ${ }^{-1}$ determined by direct calorimetric measurement by Fernandez and Hepler.

Oscillator models in unimolecular reactions, M. L. Vestal and H. M. Rosenstock, J. Chem. Phys. 35, No. 6, 2008-2016 (Dec. 1961).

The absolute reaction rate theory for the unimolecular decomposition of isolated excited molecules is applied to two models. The first considers the molecule as a set of harmonic oscillators in which only a finite amount of energy may be stored in a particular degree of freedom. In the second model the spacing between adjacent levels is assumed to decrease exponentially. The first leads to a decrease in the lifetime above that calculated for the conventional harmonic oscillator model for shortlived molecules. The second produces an increase depending directly on the rate of change of the level spacing. The effect of anharmonicity on rates is discussed.

Some physical properties of monochloro-, dichloro, and monobromoacetic acids at 1 atmosphere, A. R. Glasgow and J. Timmermans, Bull. Soc. Chim. Belbes ro, 599-622 (1961). Monochloro-, dichloro-, and monobromoacetic acids (99.8 mole percent or better) have been prepared. The following physical properties have been determined: melting point (monobromo and dichloro acids), dielectric constants of liquid and solid (monochloro and dichloro), specific heat of solid (monobromo and dichloro), and heat of fusion (dichloro). Thermal analysis of solutions of the monobromo and dichloro acids with each other, with monochloro acid, and with water was used to obtain the phase diagrams. Three polymorphic forms of monochloroacetic acid were found at normal pressures; no polymorphs were found for the dichloro and monobromo acids. Formation of a continuous series of solid solutions between monobromoacetic acid and the mastastable $\beta$-form of monochloroacetic acid suggests that this matastable form and the monobromo acid have the same crystal structure.

Intramolecular rearrangements. IV. Photolysis of 2-pentanone-4, 5, 5- $\boldsymbol{d}_{3}$, R. P. Borkowski and P. Ausloss, J. Phys. Chem. 65, 2257-2260 (1961).

The photolysis of 2-pentanone-4,5,5- $d_{3}$ in the vapor and liquid-states yields $\mathrm{D}_{2} \mathrm{C}=\mathrm{CHD}$ and $\mathrm{DHC}=\mathrm{CHD}$. These ethylenes are formed by intramolecular rearrangements in which either an $\mathrm{H}$ or a D-atom is transferred to the carbonyl group.

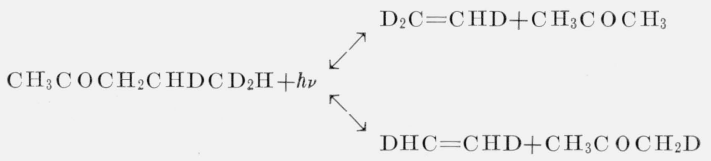

In the vapor phase the quantum yield of ethylene is independent of concentration, temperature, and intensity, whereas it decreases with increasing wavelength and oxygen pressure. The effect of oxygen is more pronounced at the longer wavelength and lower temperature which indicates that oxygen interacts only with molecules excited to a low vibrational level. The ratio $\mathrm{C}_{2} \mathrm{D}_{3} \mathrm{H} / \mathrm{C}_{2} \mathrm{H}_{2} \mathrm{D}_{2}$ is independent of intensity, but increases with increasing wavelength and ketone concentration, and diminishes with increasing temperature and oxygen pressure. These effects may be explained qualitatively in terms of the difference in the bond strength of $\mathrm{C}-\mathrm{D}$ and $\mathrm{C}-\mathrm{H}$.

In the liquid phase the quantum yield of ethylene increases, and the ratio $\mathrm{C}_{2} \mathrm{D}_{3} \mathrm{H} / \mathrm{C}_{2} \mathrm{H}_{2} \mathrm{D}_{2}$ decreases with increasing temperature. A difference of activation energy of about 1 $\mathrm{kcal} /$ mole was obtained for $\mathrm{D}$ and $\mathrm{H}$ transfer in the intramolecular rearrangement.

Electrophoretic mobilities and surface adsorption in the polystyrene latex-aliphatic soap system, C. L. Sieglaff and J. Mazur, J. Colloid Sci. 17, No. 1, 66-85 (Jan. 1962).

The electrophoretic mobilities of a polystyrene latex stabilized by straight chain aliphatic soaps were measured as a function of soap and salt concentrations. The soaps employed were alkali salts of fatty acids ranging from $\mathrm{C}_{8}$ (caprylic) soap to $\mathrm{C}_{16}$ (palmitic) soap. The salts employed were potassium and sodium choride. The results are explained by a modification of the Stern localized adsorption model which takes into account the effect of the ionic strength of the system on the rate of adsorption of soap anions by the latex particle.

It has been postulated, on the basis of these experimental data, that the chloride ions are preferably adsorbed by the latex particle, in addition to the soap ions. This requires an extension of the Stern-Langmuir adsorption isotherm into a two-component adsorption of ions of the same sign, but with different effective areas and adsorption potentials.

From the maxima in the curves representing mobilities versus soap concentration, the dependence of adsorption potential and of effective area of soap ion on the number of $\mathrm{CH}_{2}$ groups in the aliphatic chain was obtained. It was observed that within the limitations of the theoretical model employed the adsorption potential increases by approximately $600 \mathrm{cal} / \mathrm{mole}$ for each additional $-\mathrm{CH}_{2}-$ group in the soap molecule.

An equation of state for calculating the thermodynamic properties of helium at low temperatures, R. D. McCamy and R. B. Stewart (1962 2d Symp. Thermophysical Properties, January 24-26, 1962, Princeton University, Princeton, New Jersey), Progress in International Research on Thermodynamics and Transport Properties, Am. Soc. Mech. Engrs. (New York, N.Y.), p. 107 (1962).

A new equation of state for helium gas with six adjustable constants is presented. This relation is adequate for the representation of the $\mathrm{P}-\mathrm{V}-\mathrm{T}$ data and for the calculation of the entropy and enthalpy for a range of temperatures from 20 to $300 \mathrm{~K}$, with pressures to $100 \mathrm{~atm}$. A comparison of calculated volumes with the original data indicates an average arithmetic deviation of 0.07 percent and maximum deviations of 0.5 percent. A comparison of calculated pressures with original data indicates about the same average and maximum deviations. A temperature-entropy chart and a compressibility factor chart have been prepared from values calculated by this equation of state. Values of density, enthalpy and entropy, are tabulated with temperature and pressure as independent arguments.

Journal of Research 66B (Math. and Math. Phys.) No. 2, (Apr.- June 1962) 75 cents.

Hindsight technique in machine translation of natural languages. I. Rhodes and F. L. Alt

An extension of Jensen's theorem for the derivative of a polynomial and for infrapolynomials. O. Shisha.

Two matrix eigenvalue inequalities. S. Haber.

Graphs for determining the power of Student's $t$-test. M. C. Croarkin.

Journal of Research 66D (Radio Prop.) No. 4, (July-Aug. 1962) 70 cents.

Propagation problems with space radio communications. K. Rawer.

On the absolute intensity of incoherent scatter echoes from the ionosphere. K. L. Bowles, G. R. Ochs, and J. L. Green.

On the forward scattering of radio waves in the lower ionosphere. T. Hagfors.

The representation of diurnal and geographic variations of ionospheric data by numerical methods. W. B. Jones and R. M. Gallet.

The interaction between an obliquely incident plane electromagnetic wave and an electron beam in the presence of a static magnetic field of arbitrary strength. K. H. B. Wilhelmsson. (See above abstract.)

An analysis of VLF mode propagation for a variable ionospheric height. J. R. Wait.

A method for the determination of lower inonsphere properties by means of field measurements on sferics. F. B. Harris, Jr., and R. L. Tanner.

Defocusing of radio rays by the troposphere. R. E. Wilkerson.

Magnetotelluric fields in the frequency range 0.03 to 7 cycles per kilosecond: Part I. Power spectra. C. W. Horton and A. A. J. Hoffman. (See above abstract.)

Magnetotelluric fields in the frequency range 0.03 to 7 cycles per kilosecond: Part II. Geophysical interpretation. C. W. Horton and A. A. J. Hoffman. (See above abstract.) The impedance of a circular loop in an infinite conducting medium. M. B. Kraichman. 
Calibration procedures for direct-current resistance apparatus, P. P. B. Brooks, NBS Mono. 39 (Mar. 1962), 40 cents.

Thermocouple materials, F. R. Caldwell, NBS Mono. 40 (Mar. 1962) 30 cents.

Evaluation of convolution integrals occurring in the theory of mixed path propagation, J. R. Johler and C. M. Lilley, NBS Tech. Note 132 (PB161633) (1961) \$1.00.

Historical survey of fading at medium high radio frequencies, R. K. Salaman, NBS Tech. Note 133 (PB161634) (1962) 75 cents.

A study of F2-layer effects as observed with a Doppler technique, K. Davies, J. M. Watts, and D. H. Zacharisen, J. Geophys. Research 68, 601-609 (Feb. 1962).

Ionospheric effects associated with the solar flare of September 28, 1961, K. Davies, Nature Letter 193, 763-764 (Feb. 24, 1962).

Sferic observations of the severe weather on May 19, 1960, C. A. Samson and R. F. Linfield, J. Geophys, Research 67, 627-635 (Feb. 1962).

On the mean temporal variations of electron density at a fixed height in the $F$ region, A. J. Hirsh and R. W. Knecht, J. Geophys. Research 6\%, No. 2, 595-600 (Feb. 1962).

Displacement and strain-energy distribution in a longitudinally vibrating cylindrical rod with a viscoelastic coating, P. Hertelendy, J. Appl. Mechanics, No. 61-WA-30 (1962).

Comparison of United States and Canadian free-air ionization chambers, J. H. Aitken, L. De LaVergne, W. H. Henry and T. P. Loftus, Brit. J. Radiol. 35, No. 409, 65-70 (Jan. 1962)

Statistical problems arising in the establishment of physical standards, W. J. Youden, Proc. Fourth Berkeley Symp. on Math. Statisties and Probability III, 321-335 (1961).

National Bureau of Standards, Washington, D. C. and Boulder, Colorado, C. E. Moore, Astron. J. 66, No. 10 (Dec. 1961).

Rapid method for interpolating refractive index measurements, O. N. Stavroudis and L. E. Sutton, J. Opt. Soc. Am. 51, No. 3, 368-370 (Mar. 1961).

The three-dimensional nature of boundary-layer instablitity, P. S. Klebanoff, K. D. Tidstrom, and L. M. Sargent, J. Fluid Mechanies 12, Pt. 1, 1-34 (1962).

A specimen for use in investigating the stress-corrosion cracking of matals at elevated temperatures, H. L. Logan, Materials Research and Standards (ASTM Bull.) 2, No. 2, 98-100 (Feb. 1962).

Dynamic behavior of a simple pneumatic pressure reducer, D. H. Tasai and E. C. Cassidy, J. Basic Eng., 253-264 (June 1961)

Effect of porosity on Young's modulus of alumina, F. P. Knudsen, J. Am. Chem. Soc. 45, No. 2, 94-95 (Feb. 1962).
Characteristic electron energy loss measurement at low temperatures, E. M. Horl and J. A. Suddeth, J. Appl. Phys. 32, No. 12, 2521-2525 (Dec. 1961).

A new approach to the mechanical syntactic analysis of Russian, I. I. Rhodes, Mech. Transl. 6, 33-50 (Nov. 1961).

A string language for symbol manipulation based on ALGOL 60, J. H. Wegstein and W. W. Youden, Commun. ACM 5, No. 1, 54-61 (Jan. 1962).

Ray-tracing formulas for uniaxial crystals, O. N. Stavroudis, J. Opt. Soc. Am. 52, No. 2, 187-191 (Feb. 1962).

Doppler studies of the ionosphere with vertical incidence, K. Davies, Proc. IRE 50, No. 1, 94 (Jan. 1962).

Parametric behavior of an ideal two-frequency varactor, G. F. Montgomery, Proc. IRE 50, No. 1, 78-80 (1962).

Auroral zone geomagnetic micropulsations with periods of 5 to 30 seconds, W. H. Campbell and S. Matsushita, J. Geophys. Research 67, 555-573 (Feb. 1962).

On the interpretation of prominence spectra. V. The emission lines in quiescent prominences, J. T. Jefferies and F. Q. Orrall, Astrophys. J. 135, 109-121 (Jan. 1962).

Design of retarding field energy analyzers, J. A. Simpson, Rev. Sci. Instr. 22, No. 12, 1283-1293 (Dec. 1961).

Stress-strain relationships in yarns subjected to rapid impact loading. Part VIII: Shock waves, limiting breaking velocities, and critical velocities, J. C. Smith, J. M. Blandford, and K. M. Towne, Textile Research J. 32, No. 1, 67-76 (Jan. 1962).

The standards challenge, A. H. Scott, Insulation 8, No. 2, 48-50 (Feb. 1962). Average decay laws for VLF fields, J. R. Wait, Proc. IRE 50, No. 1, 53-56 (Jan. 1962).

Radiation beam mapping with photographic film, W. L. MeLaughlin, Radiology 78, No. 1, 119-120 (Jan. 1962).

Fitting refractive index data by least squares, L. E. Sutton and O. N. Stavroudis, J. Opt. Soc. Am. 51, No. 8, 901905 (Aug. 1961).

Compton scattering by $K$-shell electrons, J. W. Motz and G. Missoni, Phys. Rev. 124, No. 5, 1458-1468 (Dec. 1961). Current-limited rectifiers, G. F. Montgomery, Proc. IRS 50, No. 2, 190-193 (Feb. 1962).

* Publications for which a price is indicated (except for Technical Notes) are available only from the Superintendent of Documents, U.S. Government Printing Office, Washington 25, D.C. (foreign postage, one-fourth additional). Technical Notes are available only from the Office of Technical Services, U.S. Department of Commerce, Washington 25, D.C. (order by $P B$ number). Reprints from outside journals and the NBS Journal of Research may often be obtained directly from the authors. 